Jason M. Fletcher ${ }^{1,3}$ / Stefanie Schurer ${ }^{2,3}$

\title{
Origins of Adulthood Personality: The Role of Adverse Childhood Experiences
}

\author{
${ }^{1}$ La Follette School of Public Affairs, University of Wisconsin-Madison, Madison, WI, USA \\ ${ }^{2}$ School of Economics, University of Sydney, Sydney, Australia, E-mail: stefanie.schurer@sydney.edu.au \\ ${ }^{3}$ Institute for the Study of Labor (IZA), Bonn, Cermany, E-mail: stefanie.schurer@sydney.edu.au
}

\begin{abstract}
:
We test whether adverse childhood experiences - exposure to parental maltreatment and its indirect effect on health - are associated with age 30 personality traits. We use rich longitudinal data from a large, representative cohort of young US Americans and exploit the differences across siblings to control for the confounding influences of shared environmental and genetic factors. We find that maltreatment experiences are significantly and robustly associated with neuroticism, conscientiousness, and openness to experience, but not with agreeableness and extraversion. High levels of neuroticism are linked to sexual abuse and neglect; low levels of conscientiousness and openness to experience are linked to parental neglect. The estimated associations are significantly reduced in magnitude when controlling for physical or mental health, suggesting that adolescent health could be one important pathway via which maltreatment affects adulthood personality. Maltreatment experiences, in combination with their health effects, explain a significant fraction of the relationship between adulthood conscientiousness and earnings or human capital. Our findings provide a possible explanation for why personality traits are important predictors of adulthood labor market outcomes.
\end{abstract}

Keywords: human capital, noncognitive skills, Big Five personality traits, adverse childhood experiences, maltreatment, siblings fixed effects, Add Health

DOI: $10.1515 /$ bejeap-2015-0212

\section{Introduction}

Human capital is one of the most important determinants of an individual's long-term economic productivity and health. Traditionally, human capital has been proxied by measures of achievement test scores, years of schooling, or the type of post-secondary qualification. In recent years, however, economists have suggested that personality traits, sometimes referred to as noncognitive skills (NCS), soft skills, or character traits, are an important alternative form of human capital (Almlund et al. 2011). Although numerous proxies for adulthood personality traits have been considered in the literature, the Big Five personality traits are one of the most widely used (e.g. Fletcher 2013; Heckman and Kautz 2012; Heineck and Anger 2010; Lundberg 2013; Mueller and Plug 2006; Cameron et al. 2013; Gensowski 2014).

In this study, we explore the factors that shape the Big Five personality traits between childhood and young adulthood for a large, representative US population. Specifically, we seek to shed light on the long-term personality effects of early childhood adversity related to poor parenting behaviors, such as abuse and neglect, and explore the potential mechanisms via which maltreatment could affect personality development. By studying children's exposure to maltreatment, our study distinguishes itself from, but contributes to, an emerging literature on the economics of human development that seeks to better understand the production function of personality traits in childhood, a literature which focuses mainly on the role of positive parenting behaviors (e.g. educational investments), the education sector, and income. Our findings could be useful for researchers to better interpret the productivity-boosting effects of adulthood personality traits, and to policy makers who are concerned about the windows of opportunity to shape personality traits through the education and family policy.

Our analysis relies on the finding that personality traits are not exclusively influenced by genetic predisposition. Even though a strong genetic component has been shown, at least $50 \%$ of the variation in personality traits can be attributed to personal experiences (Turkheimer 2000; Turkheimer et al. 2003; Krueger et al. 2008; Borkenau et al. 2001). Psychologists have suggested that variations in adulthood personality may have their origins in childhood experiences associated with exposure to specific parenting styles (Eisenberg et al. 2014 on conscientiousness) and health problems (Caspi and Roberts 2001; Caspi, Roberts, and Shiner 2005). In this 
study, we therefore focus our attention on adverse childhood experiences in the form of exposure to caregiver maltreatment, and their effect on adolescent mental and physical health.

Children who have experienced abuse and neglect are at increased risk for a number of problematic developmental outcomes, including learning problems, problems relating to peers, internalizing symptoms, and externalizing symptoms (Petersen, Joseph, and Feit 2014 for a review). As adults, these children are more likely to suffer physical health problems, to engage in risky behaviors (Felitti et al. 1998; Widom et al. 2012), and to develop mood disorders (Fletcher 2009; Kaufman et al. 2004; Widom, DuMont, and Czaja 2007) and psychopathologies (Clark et al. 2010; Putnam 2006; Spila et al. 2008; Tyrka et al. 2009; Widom, Czaja, and Paris 2009); they are also more likely to be involved in criminal activity (Currie and Tekin 2012), which is consistent with the observation that children with maltreatment experiences are often impaired in their prosocial and ethical behavior development (Koenig, Cicchetti, and Rogosch 2004). It is for these reasons that we hypothesize that maltreatment experiences influence an individual's development of "enduring patterns of thoughts, feelings, and behaviors" (Roberts, Walton, and Viechtbauer 2006,1) which define personality traits. A recent study by Hengartner et al. (2015) emphasized the importance of the link, but concluded that it is a highly "understudied field" (p. 1).

To investigate the long-term impact of maltreatment on personality, we use longitudinal data from a US American cohort study (Add Health) that followed cohort members' health trajectories from early adolescence into young adulthood. We estimate the relationship between adverse childhood experiences and responses to an adulthood personality questionnaire that was collected years after the exposure to (before age 12) and report of (around age 22) adversity. The dataset has the advantage that it contains information on maltreatment and personality for siblings, which we exploit in our empirical framework to control for some of the confounding factors that may bias the treatment effects of interest (Bound and Solon 1999; Conley, Pfeiffer, and Velez 2007; Moffitt et al. 2011). We further explore whether adolescence health trajectories - that were reported between ages 15 and 22 - mediate the effect of childhood maltreatment on personality. Finally, we assess the extent to which the estimated relationship between adulthood personality and adulthood earnings (e.g. Fletcher 2013) and educational attainment (e.g. Lundberg 2013) is reduced when controlling for adverse childhood experiences.

\subsection{Literature Review}

A number of different personality inventories have been developed by psychologists, but the Five-Factor Model is broadly accepted as a meaningful and consistent construct for describing human differences by psychologists (McCrae and Costa 2008). ${ }^{1}$ Personality psychologists have demonstrated strong links between the Big Five personality traits and occupational choice (Filer 1986), job performance (e.g. Judge et al. 1999), academic achievement (Poropat 2009), or healthy lifestyles (e.g. Hampson et al. 2006; Roberts et al. 2007). Various studies have established that low levels of neuroticism and high levels of conscientiousness promote both physical and mental well-being (Goodwin and Friedman 2006), and life expectancy is associated with youth conscientiousness (Kern and Friedman 2008; Kern et al. 2009).

Economists have added to this literature by showing that emotional stability and openness to experience are strongly associated with labor market earnings (e.g. Mueller and Plug 2006; Heineck and Anger 2010; Fletcher 2013), even for highly talented people (Gensowski 2014). Both high levels of youth conscientiousness and openness to experience increase the probability to obtain a university degree (Lundberg 2013; Schurer, Kassenboehmer, and Leung 2015), while conscientiousness and emotional stability are associated with high performance on cognitive ability tests (Borghans et al. 2011).

What factors shape adulthood personality traits beyond genetic disposition is less well researched. Earlier work contended that individuals are born with a fixed temperament, and changes between childhood and adulthood occur deterministically, a process often referred to as maturation (for an overview, see McCrae et al. 2000). The path dependency between childhood temperament and adulthood personality has been demonstrated multiple times (e.g. Asendorpf, Denissen, and Van Aken 2008; Caspi et al. 2003; Caspi and Silva 1995; Deal et al. 2005; McAdams and Olson 2010; Moffitt et al. 2011). The earlier work on the Five-Factor Model also assumed that personality traits stabilize in young adulthood, but more recent evidence has shown that adulthood personality traits may even change beyond the age of 50 (Fraley and Roberts 2005; Roberts and DelVecchio 2000; Roberts and Mroczek 2008; Roberts, Walton, and Viechtbauer 2006; Roberts, Wood, and Caspi 2008; Specht et al. 2014). Some studies focus on the impact of social roles (Roberts, Wood, and Smith 2005), life events experienced in adulthood (Specht, Egloff \& Schukle 2011;, Cobb-Clark and Schurer 2012, Luhmann et al. 2014) or adolescence (Elkins, Kassenboehmer, and Schurer 2017), secondary schooling (Dahmann and Anger 2014), or tertiary education (Lüdtke et al. 2011; Schurer, Kassenboehmer, and Leung 2015).

Traditionally, the role of the environment in which an individual grew up was not considered relevant, but in recent years the role that parents play in the personality formation process has been acknowledged (e.g. 
Eisenberg et al. 2014). An emerging literature in the economics of human development explores the importance of positive parenting behaviors - such as educational investments and parenting styles - as inputs in the human capital formation process (see Cobb-Clark, Salamanca, and Zhu 2016 for a theoretical discussion). Most of the work focuses on the development of the cognitive and NCS of children (e.g. Cunha and Heckman 2008; Cunha, Heckman, and Schennach 2010; Del Bono et al. 2014; Attanasio et al. 2015). Yet, little empirical research has been conducted on the effect of negative parenting behaviors - when parents fail to help their children to regulate their physiology and behavior in the early years of life - on personality development. This failure is often summarized as maltreatment and comprises sexual, psychological, or physical abuse or neglect. Abuse refers to active harm through inappropriate or aggressive behavior, whereas neglect refers to a lack of attention to the basic needs of a child.

There are many pathways via which maltreatment experiences may impact on adulthood personality. Foremost, maltreatment has a direct effect on the development of the brain. Several studies have shown the biological brain differences between maltreated and non-maltreated children (see Petersen, Joseph, \& Feit 2014 for references). These include differences in the areas of the brain which are involved in higher-order cognitive processes - executive function - that aid in the monitoring and control of emotions and behavior (prefrontal cortex) and the formation and storage of memories associated with emotional events (amygdala). Some argue that the personality trait conscientiousness measures executive function, while neuroticism measures emotional instability and urgency (e.g. Kern et al. 2009). This would suggest that maltreated children would show lower levels of conscientiousness and higher levels of neuroticism early in life, facets of a child's temperament that may have the potential to mature into fixed adulthood traits.

Childhood maltreatment experiences could be linked with adulthood personality traits because their extreme manifestations proxy behavioral or emotional problems that were triggered by those experiences. The psychological literature has demonstrated a significant link between maltreatment and childhood temperament problems (Perry et al. 1995) and the onset of a personality disorder (see Galaif et al. 2001, Spila et al. 2008; Tyrka et al. 2009). While personality traits are distinct from personality disorders, there is now a considerable body of research that understands personality disorders as maladaptive and/or extreme variants of the FiveFactor Model personality structure (Widiger and Trull 2007; Krueger and Eaton 2010; Trull and Widiger 2013). Samuel and Widiger (2008) and Widiger et al. (2005), who successfully mapped Axis II disorders into maladaptive variants of the 30 facets of the Five-Factor Model, showed that dependent and avoidant personality disorders and borderline syndrome correlate strongly with depressive and self-conscious facets of neuroticism, obsessive-compulsive disorder correlates with conscientiousness, and schizoid personality disorder correlates with extraversion.

Alternatively, maltreatment could directly affect the mental and physical health of children and adolescents, and that it is the experience of persistent health problems that influences personality development. The evidence is ample that maltreated children tend to have a higher risk of suffering from internalizing or externalizing problems, heightened anxiety, and emotional reactivity. Victims of sexual abuse are also more likely to suffer from attention and learning difficulties (e.g. Koenen et al. 2003; Krueger et al. 2008). Consistent with suggestions made by Caspi and Roberts (2001) and Caspi, Roberts, and Shiner (2005) that adulthood personality differences may be preceded by childhood health problems, we would expect maltreatment to influence adulthood personality via its effect on health.

Finally, maltreatment experiences and adulthood personality may just be correlated because they have the same underlying causes. For instance, sustained experiences of poverty and environmental stressors may cause independently both parents to neglect their children and personality development. These factors may also shape independently cognitive ability, physical or mental health, health behaviors, and adulthood socioeconomic status. This is a selection effect that needs to be controlled for to establish whether maltreatment leads to long-term personality problems. ${ }^{2}$

To the best of our knowledge, we are the first to explore in detail the relationship between adulthood personality traits and parenting-related adverse childhood experiences. The only exception is Hengartner et al. (2015), who show strong unadjusted associations between adulthood personality traits and self-reported maltreatment experiences (emotional, physical and sexual abuse, and neglect) for 1,170 subjects from a population-based community survey. The authors emphasize that the relationship between personality traits and maltreatment is a highly "understudied field" (Hengartner et al. 2015, 1).

We improve upon Hengartner et al. (2015) in four ways: (1) We conduct our analysis with data on a nationally representative cohort; (2) We are able to control for a large set of confounding factors including poverty, peers, and genetic disposition that are shared between siblings; (3) We are able to comment on the potential pathways via which adverse childhood experiences impact upon adulthood personality, under the assumption that we adequately control for other factors that influence maltreatment, personality, and mediators; and (4) Although also self-reported, our measures of maltreatment were collected 12 years before the personality traits were assessed. 


\section{Data: National Longitudinal Study of Adolescent Health}

The data in this study come from the confidential version of the National Longitudinal Study of Adolescent Health (Add Health). Add Health, one of the most comprehensive surveys of adolescents ever undertaken, is a school-based, longitudinal study of the health-related behaviors of adolescents and their outcomes in young adulthood (Udry 2003). Beginning with an in-school questionnaire administered to a nationally representative sample of students in grades 7 through 12 in 1994-95 (Wave 1: mean age 15), the study followed up with a series of in-home interviews of students approximately 1 year (Wave 2 in 1996: mean age 16), 6 years (Wave 3 in 2001/2002: mean age 22), and 12 years later (Wave 4 in 2007/2008: mean age 29).

Other sources of data include questionnaires for parents, siblings, fellow students, and school administrators. By design, the Add Health survey included a sample stratified by region, urbanicity, school type, ethnic mix, and size. Preexisting databases (e.g. census data) have been linked with the individuals in the sample and provide information about neighborhoods and communities. Of the 20,745 students surveyed during Wave 1, nearly $15,000(75 \%)$ have been followed longitudinally in the Wave 4 survey. For $52 \%$ or 10,693 individuals of the Wave 1 sample, we have personality data from Wave 4 and maltreatment information from Wave 3 available. There are 5,470 siblings in the full Wave 1 sample, of which 3,813 are followed in Waves 3 and 4 and 3,098 are in a family where another sibling was also followed in Waves 3 and 4 . Of these 3,098 eligible respondents, 2,453 have information on both maltreatment and personality measures. We lose an additional 134 individuals because either the respondent or his/her sibling has missing cognitive ability information or depression measures (which we do not impute in the data), leaving our analysis sample of 2,319. The majority of families in the siblings sample has two siblings (92\%).

We assessed whether the siblings sample is systematically different in observable characteristics from the full available sample (Table 5, Technical Appendix). We find very few differences between samples, especially with respect to levels of maltreatment and baseline characteristics. We do find differences in birthweight, but this is to be expected because the siblings sample includes twins. Linking the likelihood of being in our final sibling analysis sample with Wave 1 family characteristics, we find no associations between the indicator for being in our analysis sample and maternal education or an indicator for black families (Table 6, Technical Appendix). We find a very small association with family income, suggesting that a $\$ 10,000$ difference in income raises the likelihood of inclusion in our analysis by less than 1 percentage point. We conclude that our siblings estimation sample is not systematically different to the full sample, and therefore sample selection bias should be negligible.

\subsection{Young Adulthood Personality Traits}

In Wave 4, data were collected on personality with the 20-item short-form version of the 50-item International Personality Item Pool-Five-Factor Model (IPIP-FFM) known as the Mini-IPIP (Donnellan et al. 2006). Baldasaro, Shanahan, and Bauer (2013) suggest that the Mini-IPIP has a five-factor structure that represents extraversion, neuroticism, agreeableness, conscientiousness, and openness to experience. Most of the scales have acceptable reliability, all the scales have partial or full metric invariance, and the scales exhibit sufficient criterion validity.

${ }^{3}$ As is standard in the literature, we use factor analysis to extract the first principal factor for each domain and standardize it to mean 0 and standard deviation 1 (see Almlund et al. 2011,32). ${ }^{4}$ Table 7 (Technical Appendix) lists all 20 items.

\subsection{Maltreatment Indicators}

In Wave 3, respondents were asked four questions on how their parents (or adult caretakers) treated them before they were in sixth grade (age 12). Specifically, they were asked whether and how often:

1. Parents (or other adult caregivers) had not taken care of their basic needs, such as keeping them clean or providing food or clothing.

2. Parents (or other adult caregivers) slapped, hit, or kicked them.

3. Parents (or other adult caregivers) had touched them in a sexual way, forced them to touch him or her in a sexual way, or forced them to have sexual relations.

4. Parents (or other adult caregivers) left them home alone when an adult should have been with them. 
We use two measures to use the maltreatment information. First, we derive from factor analysis over all four response categories a continuous measure of maltreatment. This measure captures the intensity of maltreatment, without specifying the underlying causes of the maltreatment. Second, to separately identify the effects and intensity of the four variants of maltreatment, we follow Currie and Tekin (2012) to construct for each event a binary indicator that takes the value 1 if the respondent reports that he or she experienced the respective maltreatment more than 10 times, and 0 otherwise. One reason for considering only the higher frequency of traumatic events is the assumption that chronic abuse - in contrast to one-off events - will have a long-term impact on behavior. Currie and Tekin (2012) and Fletcher (2009) provide further details that the information provided in the maltreatment report is reliable and that it was collected in an appropriate way. ${ }^{5}$

In our data, $50 \%$ of all sample members reported the experience of some form of abuse during their childhood. Any sexual abuse was reported by $5 \%$ of the sample (535), but on a regular basis ( $>10$ times) around $1 \%$ (106) of the sample reported sexual abuse. While almost one-third of the sample reports to have been ever spanked, hit, or kicked, over 6\% (642) experienced physical abuse on a more regular basis (>10 times). Regular neglect of basic needs or having been left alone (>10 times) occurred for 3\% (321) and 9\% (962) of the sample, respectively. Important gender differences emerge only for the report of frequent sexual abuse: female cohort members are four times more likely of reporting sexual abuse than male cohort members.

\subsection{Mediators of the Effect of Maltreatment on Adulthood Personality}

\subsubsection{Adolescence Personality and Cognitive Ability}

In Wave 1, cohort members were asked to answer 21 questions regarding their personality that can be mapped into three of the five factors - neuroticism, extraversion, and conscientiousness - using the IPIP/NEO-PI-R as guidelines (Young and Beaujean 2011). All questions are listed in Table 8 (Technical Appendix). Young and Beaujean (2011) compared these questions with items from the IPIP (Goldberg et al. 2006) version of the NEOPI-R (Costa and McCrae 1992). They subjected all available items to an item-level factor analysis to determine what items to keep, as well as the dimensionality of the domains the items were measured. They concluded that 13 of the original 21 items can be reliably used to generate measures of childhood neuroticism (6 items), extraversion ( 3 items), and conscientiousness (4 items). ${ }^{6}$ To construct an index for each childhood personality trait, we use factor analysis.

To measure cognitive ability, we follow Fletcher (2013) and Lundberg (2013) and use from Wave 1 answers to the Peabody Picture Vocabulary Test (PVT) and self-reported school math grades.

\subsubsection{Adolescent Physical and Mental Health}

We construct standard measures of physical and mental health problems that were reported between Wave 1 and Wave 3. These include general health status, chronic health conditions (asthma, obesity, diabetes, obesity), various markers for sensory or motor skill problems, Attention Deficit Hyperactivity Disorder (ADHD), learning disabilities, and depression. We construct measures of health between early-to-late adolescence, so that they reflect health problems that are likely to have set on after the experience of maltreatment. Table 9 (Technical Appendix) describes these variables in detail.

Table 1 presents a short description of all variables used for the analysis and their summary statistics are reported in Table 5 (Technical Appendix).

Table 1: Control variables for regression models.

Childhood Maltreatment indicators (before grade 6, or age 12)

Sexual abuse more than 10 times $(0,1)$

Slapped more than 10 times $(0,1)$

Left alone when shouldn't have more than 10 times $(0,1)$

Neglected basic needs more than 10 times $(0,1)$

or

Continuous measure of maltreatment obtained from factor analysis

Note: Data on maltreatment experiences was collected in Wave 3, with reference to experiences that occurred before grade 6 (age 12)

Baseline control variables

Wave 1: Birthweight, sex, family characteristics

Wave 4: Age 


\section{Mediation analysis}

1.

Wave 1: Neuroticism, extraversion, conscientiousness

2.

Wave 1: Peabody vocabulary test, math grade (self-reported)

3.

Wave 2: Measured obesity $(\mathrm{BMI}>30)$ (average age 16)

Wave 3: Asthma, Epilepsy, Blindness (average age 22)

Wave 4: Diabetes if occurred before age 18

4.

Wave 1: Depression, Learning disability (average age 15)

Wave 3: ADHD (average age 22)

5.

Wave 4: Years of education, weekly earnings

\section{Adolescence personality (average age 15)}

Cognitive ability (average age 15)

Physical health problems
with feet (average age 15)

Mental health problems

Adult socioeconomic status (average age 29)

\section{Empirical Framework}

To test whether experience of maltreatment is associated with adulthood personality, we use ordinary least squares (OLS) linear regression and siblings fixed effects (S-FE) models. In eq. (1), the personality trait $k\left(P T_{i}^{k}\right)$ is a linear function of maltreatment and basic control variables:

$$
P T_{i}^{k}=\alpha^{k}+M T_{i}^{\prime} \beta^{k}+X_{i}^{\prime} \gamma^{k}+\varepsilon_{i}^{k}
$$

where $\varepsilon_{i}^{k}$ captures all unobservable shocks that affect personality trait $k$, but are independent of variables captured in vector $X_{i}{ }^{\prime}$, and $\alpha^{k}, \beta^{k}$ and $\gamma^{k}$ are parameters to be estimated. The vector $M T_{i}$ contains either a continuous summary measure of maltreatment or four binary variables that indicate whether the individual experienced regularly maltreatment before grade 6 (sexual abuse, being beaten, left alone, neglected). The vector $X_{i}^{\prime}$ controls for pretreatment characteristics including age, being female, family characteristics, and birthweight.

The above outlined model considers only variation between families and does not control for unobserved family factors that may potentially confound the treatment effects of interest. To control for some of these confounding factors, we exploit the differences between siblings (S-FE model). In eq. (2), each individual has now subscript $f$, which represents the family, and subscript $i$ which represents sibling $i$ within family $f$. On the righthand side of eq. (2), we include only variables that vary between siblings $\left(M T_{i f}, Z_{i f}\right)$.

$$
P T_{i f}^{k}=\alpha^{k}+M T_{i f}^{\prime} \beta^{k}+Z_{i f}^{\prime} \gamma^{k}+\mu_{f}^{k}+\eta_{i f}^{k}
$$

The error term is now broken down into two components: $\mu_{f}^{k}$ is a family fixed effect and $\eta_{i f}^{k}$ is the error specific to each sibling $i$ in family $f$. The family fixed effect could represent, for instance, the level of familial conflict, family-specific behavioral styles, or a genetic proneness to disease. To eliminate this family fixed effect, we difference across the siblings (e.g. 1,2) in each family eq. (3).

$$
P T_{1 f}^{k}-P T_{2 f}^{k}=\left(M T_{1 f}-M T_{2 f}\right)^{\prime} \beta^{k}+\left(Z_{1 f}-Z_{2 f}\right)^{\prime} \gamma+\left(\mu_{f}^{k}-\mu_{f}^{k}\right)+\left(\eta_{1 f}^{k}-\eta_{2 f}^{k}\right) .
$$

The S-FE approach improves upon the OLS model because it controls for difficult-to-measure shared background components. However, as with most empirical models used to analyze observational data, it has its limitations. On the one hand, the S-FE approach exploits only variation within families and therefore is an inefficient estimator (e.g. Conley, Pfeiffer, and Velez 2007, 1095). More important is that the estimated coefficients may still be biased if the differences of unobservable factors between siblings 1 and $2\left(\eta_{1 f}^{k}-\eta_{2 f}^{k}\right)$ are correlated with differences in both maltreatment and personality. This approach would fail to identify a causal effect of maltreatment on personality, if, e.g. both siblings were maltreated, but only one sibling will report the abuse due to being more willing to share maltreatment experiences (e.g. being more extraverted or open to experiences) or due to inflating negative experiences (e.g. being more neurotic). As we cannot rule out such possibility with certainty, the S-FE results do not warrant a causal interpretation.

We have sufficient variation in our data between siblings on most variables, which is the main requirement for this approach to yield efficient estimates (Bound and Solon 1999). In Table 2, we report the number of siblings who differ in outcomes and treatment. Between $84 \%$ (Agreeableness) and 87\% (Extraversion) of the sibling pairs differ in their personality scores. The numbers of sibling pairs who report differences in maltreatment are 
in ascending order: 41 for sexual abuse (1.8\%), 160 for neglect $(7.0 \%), 237$ for slapped or beaten $(10.2 \%)$, and 336 for left alone (14.5\%).

Table 2: Number of sibling-pairs in the siblings fixed effects model with differences in outcomes and treatment.

\begin{tabular}{llll}
\hline & $\mathbf{N r} \neq \mathbf{0}$ & Sample size & $\mathbf{\%}$ \\
\hline Outcome in Wave 4 & & & \\
Extraversion & 2,018 & 2,319 & 87.02 \\
Neuroticism & 2,010 & 2,319 & 86.68 \\
Agreeableness & 1,956 & 2,319 & 84.35 \\
Conscientiousness & 2,004 & 2,319 & 86.42 \\
Openness to experience & 1,974 & 2,319 & 85.12 \\
Treatment before grade 6 & & & \\
Frequent sexual abuse & 41 & 2,319 & 1.77 \\
Frequent slapped/beaten & 237 & 2,319 & 10.22 \\
Frequent left alone & 336 & 2,319 & 14.50 \\
Frequent neglect of basic & 160 & 2,319 & 6.90 \\
needs & & & \\
\hline
\end{tabular}

\subsection{Mediation Analysis}

To better understand the potential pathways via which childhood maltreatment affects adulthood personality, we conduct a mediation analysis by adding blocks of variables separately that capture: (1) adolescent personality ${ }^{7},(2)$ adolescent cognitive skills, (3) adolescent physical health conditions, or (4) adolescent mental health conditions.

The mediation analysis is conducted on the S-FE model, as described in eq. (4). Here $\left(C_{1 f}-C_{2 f}\right)$ describes the difference in the block of control variables capturing the potential mediators between siblings 1 and 2 .

$$
P T_{1 f}^{k}-P T_{2 f}^{k}=\left(M T_{1 f}-M T_{2 f}\right)^{\prime} \beta^{k}+\left(Z_{1 f}-Z_{2 f}\right)^{\prime} \gamma+\left(C_{1 f}-C_{2 f}\right)^{\prime} \pi+\left(\mu_{f}^{k}-\mu_{f}^{k}\right)+\left(\eta_{1 f}^{k}-\eta_{2 f}^{k}\right) .
$$

The parameters in vector $\pi$ capture the association of the difference in these control variables with adulthood personality. If adding the block of variables reduces the estimated association between maltreatment and adulthood personality $\left(\beta^{k}\right)$, then this would be evidence in favor of the hypothesis that maltreatment affects adulthood personality via this particular channel (McKinnon, Fairchild, and Fritz 2007, 597). Three assumptions must hold to interpret the results obtained from mediation analysis using our S-FE model as causal (see Judd and Kenny 2010; McKinnon, Fairchild, and Fritz 2007; for a review): (1) there is no reverse causality between adult personality and the mediator (e.g. adolescent mental health) or the mediator and maltreatment experiences; (2) There is no measurement error in the mediator or in reported maltreatment experiences; (3) There are no unobserved factors that cause both mental health problems and personality in adulthood.

First, in our empirical setting, we are likely to exclude the case of reverse causality because of temporal precedence. Maltreatment experiences refer to a period before grade 6, the potential mediators are measured after grade 6 but before adulthood, and personality outcomes are measured strictly after maltreatment experiences and potential mediators. Second, it is likely that measurement error occurs both in the report of maltreatment experiences and the potential mediators, although of unknown magnitudes; hence we cannot exclude the possibility that our mediation analysis yields bias estimates. Finally, although the S-FE model controls for all family-specific background variables that could affect both maltreatment and potential mediators, there is still the possibility that unobservable factors that are not shared between siblings impact independently on maltreatment experiences and the mediators. In this case, it would be inappropriate to interpret reduced coefficient estimates of $\beta^{k}$ as evidence of a causal channel running from maltreatment to adulthood personality via the mediator. ${ }^{8}$

Because we cannot assume with certainty that all three modeling assumptions are satisfied, we do not interpret our mediation analysis as causal. However, to make the flow of the discussion easier, we will use the term "is mediated by" or "is not mediated by" to indicate whether a potential pathway is more or less likely.

To complete our analysis, we also include all blocks of control variables simultaneously to assess whether maltreatment affects adulthood personality, over and above the influence of all early-to-late adolescence mediation variables. Finally, we add to this full information on adulthood socioeconomic status (SES) to assess whether childhood maltreatment is correlated with adulthood personality possibly because of its effect on adulthood SES. ${ }^{9}$ 


\section{Estimation Results}

In this section, we discuss the estimated associations between childhood exposure to parental maltreatment as measured by a continuous summary measure of maltreatment - and adulthood personality for both OLS and the S-FE models using a sample of 2,319 siblings. The OLS model that includes all control variables - but not adulthood SES - yields an adjusted $R$-squared in order of magnitudes: (1) neuroticism (12.0\%), (2) openness to experience $(10.5 \%)$, (3) agreeableness $(10.2 \%)$, (4) conscientiousness $(7.3 \%)$, and (5) extraversion (5.1\%). Each block of variables adds significantly $(p$-value $<0.01)$ to the explained variation of the respective personality traits.

Figure 1 reports the estimated regression coefficient of the effect of maltreatment (standardized to mean 0 , SD 1) on each of the five personality traits obtained from a basic and a full estimation model, and its $90 \%$ confidence intervals. The dark-grey spike refers to the OLS estimates, whereas the light-grey spikes refer to the S-FE models. In the OLS model with basic control variables, maltreatment experiences are significantly positively associated with neuroticism $(0.15 \mathrm{SD})$ and extraversion $(0.03 \mathrm{SD}$, not significant) and negatively associated with agreeableness $(-0.07 \mathrm{SD})$, conscientiousness $(-0.10 \mathrm{SD})$, and openness to experience $(-0.05 \mathrm{SD}$, not significant). When controlling for family fixed effects, the associations for neuroticism are reduced to $0.09 \mathrm{SD}$, but they remain significant at the $1 \%$ level. The associations with openness to experience increase in magnitude to -0.06 $\mathrm{SD}$ and are now significant at the $5 \%$ level. In contrast, family fixed effects explain to a large degree the association between maltreatment and conscientiousness, as the estimated coefficient drops by over $50 \%$ from -0.10 $\mathrm{SD}$ (significant at the $1 \%$ level) to $-0.05 \mathrm{SD}$ (not significant), and explain entirely the negative association with agreeableness $(-0.01 \mathrm{SD})$.

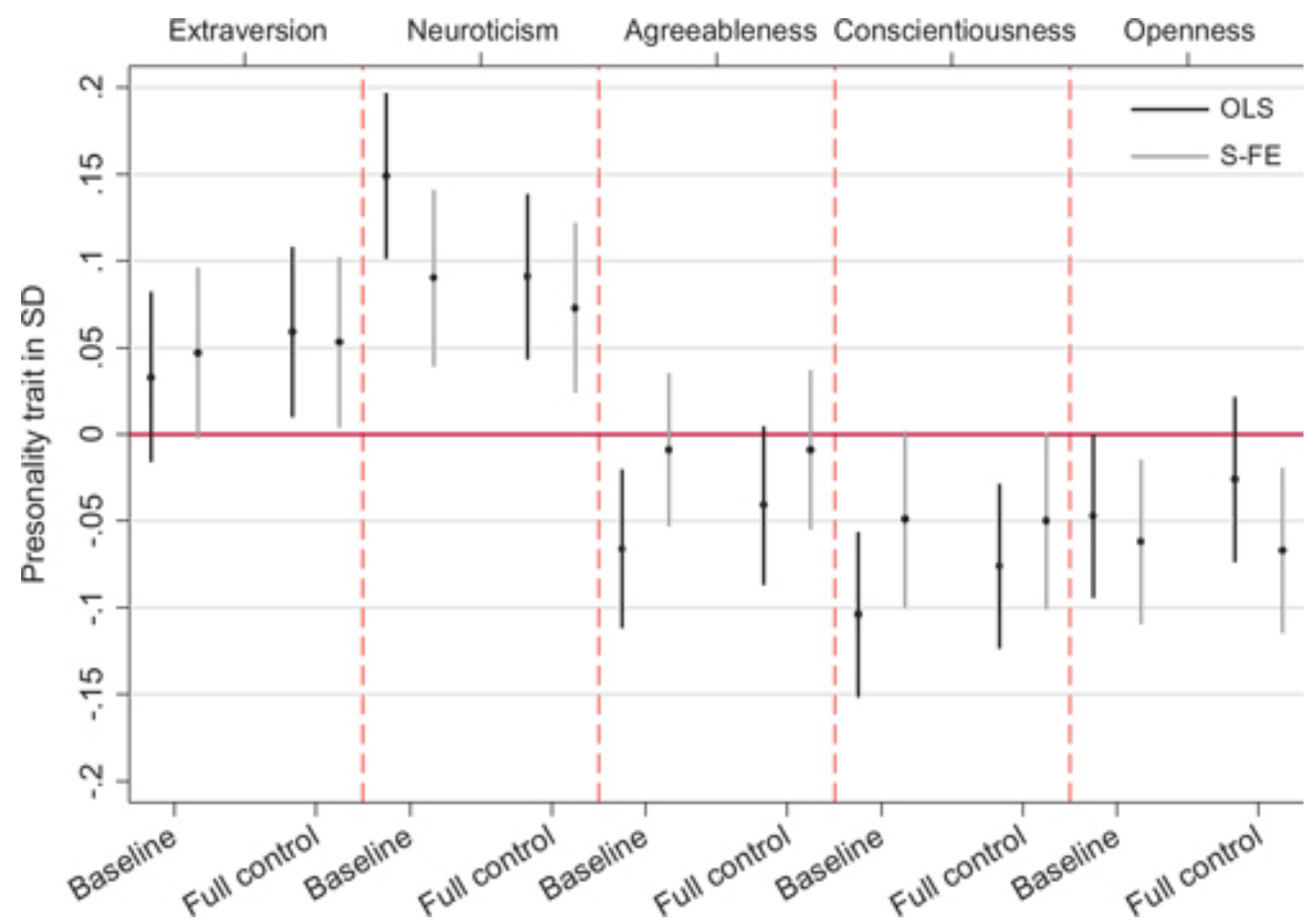

Figure 1: Estimated coefficient on continuous summary measure of maltreatment (standardized to mean 0 and standard deviation 1) for both ordinary least squares (OLS) and siblings fixed effects (S-FE) models. Spikes depict $90 \%$ confidence intervals. The sample size is 2,319 siblings. The baseline model includes controls for age, gender, family characteristics, and birthweight. The full control model includes additionally adolescent personality, adolescent cognitive ability, adolescent physical health problems, and adolescent mental health problems. Full estimation results are reported in Table 10 (Technical Appendix).

The association between early-life maltreatment experiences and neuroticism is also robust to the inclusion of potential confounders such as adolescent personality, cognitive ability, or physical or mental health problems. When controlling for the potential pathways via which early-life maltreatment experiences could affect adulthood neuroticism, the association remains robust and significant at the $5 \%$ level in the S-FE model $(0.07$ $\mathrm{SD})$. Furthermore, the negative relationship between early-life maltreatment experiences and openness to experience for sibling comparisons is even slightly stronger when controlling for these potential pathways $(-0.07$ SD). Finally, we observe a statistically significant relationship between maltreatment experiences and extraver- 
sion when controlling for childhood and adolescent developmental outcomes, independent of the estimation method (OLS: $0.06 \mathrm{SD}$, significant at the $5 \%$ level, S-FE $0.05 \mathrm{SD}$, significant at the $10 \%$ level).

We have therefore shown that maltreatment experiences are robustly associated with neuroticism and openness to experience, and to some extent with conscientiousness and extraversion. We find no stable relationship between maltreatment experiences and agreeableness. ${ }^{10}$ However, these findings do not tell us which maltreatment experiences - abuse or neglect - are the driving forces in the maltreatment-personality nexus. In Table 3, we therefore report the associations between adult personality traits and four different types of frequent maltreatment experiences using the S-FE model only. Each type of maltreatment is coded as a dummy variable that takes the value 1 if the individual reported that sexual abuse (or being slapped, left alone, or neglect of basic needs) occurred more than ten times before grade 6. Column (1) reports the estimation results for the S-FE model which controls for baseline characteristics. In column (2) to (5), we add individually blocks of control variables that capture adolescent information on personality (2), cognitive ability (3), physical health (4), and mental health (5). In column (6), we add all blocks of control variables simultaneously. In column (7), we additionally add to the full estimation model from column (6) adult SES information.

Table 3: Estimation results siblings fixed effects model $(N=2,319)$.

\begin{tabular}{|c|c|c|c|c|c|c|c|}
\hline & Baseline & $\begin{array}{l}+ \text { Child } \\
\text { Temp } \\
\text { (2) }\end{array}$ & $\begin{array}{l}\text { + Cogn. } \\
\text { Ability } \\
\text { (3) }\end{array}$ & $\begin{array}{l}+ \\
\text { Phys.Hea } \\
\text { (4) }\end{array}$ & $\begin{array}{l}+ \\
\text { HMental- } \\
\text { Health } \\
\text { (5) }\end{array}$ & $\begin{array}{l}+ \text { All } \\
\text { controls } \\
\text { (6) }\end{array}$ & $\begin{array}{l}\text { +All } \\
\text { control } \\
\text { +Adult } \\
\text { SES } \\
\text { (7) }\end{array}$ \\
\hline \multicolumn{8}{|l|}{ Extraversion } \\
\hline Sexual abuse & $\begin{array}{l}-0.025 \\
(0.206)\end{array}$ & $\begin{array}{l}-0.104 \\
(0.202)\end{array}$ & $\begin{array}{l}-0.000 \\
(0.206)\end{array}$ & $\begin{array}{l}-0.039 \\
(0.207)\end{array}$ & $\begin{array}{l}-0.011 \\
(0.208)\end{array}$ & $\begin{array}{l}-0.089 \\
(0.204)\end{array}$ & $\begin{array}{l}-0.033 \\
(0.203)\end{array}$ \\
\hline Being slapped & $\begin{array}{l}0.027 \\
(0.088)\end{array}$ & $\begin{array}{l}0.045 \\
(0.087)\end{array}$ & $\begin{array}{l}0.015 \\
(0.088)\end{array}$ & $\begin{array}{l}0.032 \\
(0.088)\end{array}$ & $\begin{array}{l}0.024 \\
(0.088)\end{array}$ & $\begin{array}{l}0.031 \\
(0.087)\end{array}$ & $\begin{array}{l}0.022 \\
(0.087)\end{array}$ \\
\hline Left alone & $\begin{array}{l}0.129^{* * *} \\
(0.074)\end{array}$ & $\begin{array}{l}0.119 \\
(0.073)\end{array}$ & $\begin{array}{l}0.135^{* * *} \\
(0.074)\end{array}$ & $\begin{array}{l}0.113 \\
(0.074)\end{array}$ & $\begin{array}{l}0.136^{* * *} \\
(0.075)\end{array}$ & $\begin{array}{l}0.120 \\
(0.073)\end{array}$ & $\begin{array}{l}0.118 \\
(0.073)\end{array}$ \\
\hline Neglect of needs & $\begin{array}{l}-0.130 \\
(0.106)\end{array}$ & $\begin{array}{l}-0.112 \\
(0.105)\end{array}$ & $\begin{array}{l}-0.130 \\
(0.106)\end{array}$ & $\begin{array}{l}-0.120 \\
(0.106)\end{array}$ & $\begin{array}{l}-0.120 \\
(0.107)\end{array}$ & $\begin{array}{l}-0.112 \\
(0.105)\end{array}$ & $\begin{array}{l}-0.120 \\
(0.104)\end{array}$ \\
\hline $\begin{array}{l}R \text {-squared } \\
\text { Neuroticism }\end{array}$ & 0.003 & 0.026 & 0.009 & 0.012 & 0.004 & 0.036 & 0.044 \\
\hline Sexual abuse & $\begin{array}{l}0.499^{* *} \\
(0.212)\end{array}$ & $\begin{array}{l}0.578^{*} \\
(0.208)\end{array}$ & $\begin{array}{l}0.491^{* *} \\
(0.211)\end{array}$ & $\begin{array}{l}0.419^{* *} \\
(0.211)\end{array}$ & $\begin{array}{l}0.394^{* * *} \\
(0.212)\end{array}$ & $\begin{array}{l}0.446^{* *} \\
(0.207)\end{array}$ & $\begin{array}{l}0.410^{* *} \\
(0.207)\end{array}$ \\
\hline Being slapped & $\begin{array}{l}0.000 \\
(0.090)\end{array}$ & $\begin{array}{l}-0.005 \\
(0.089)\end{array}$ & $\begin{array}{l}-0.005 \\
(0.090)\end{array}$ & $\begin{array}{l}-0.010 \\
(0.090)\end{array}$ & $\begin{array}{l}0.028 \\
(0.090)\end{array}$ & $\begin{array}{l}-0.001 \\
(0.088)\end{array}$ & $\begin{array}{l}0.002 \\
(0.088)\end{array}$ \\
\hline Left alone & $\begin{array}{l}0.050 \\
(0.077)\end{array}$ & $\begin{array}{l}0.060 \\
(0.075)\end{array}$ & $\begin{array}{l}0.061 \\
(0.076)\end{array}$ & $\begin{array}{l}0.062 \\
(0.076)\end{array}$ & $\begin{array}{l}0.039 \\
(0.076)\end{array}$ & $\begin{array}{l}0.067 \\
(0.075)\end{array}$ & $\begin{array}{l}0.068 \\
(0.074)\end{array}$ \\
\hline Neglect of needs & $\begin{array}{l}0.319^{*} \\
(0.110)\end{array}$ & $\begin{array}{l}0.291^{*} \\
(0.107)\end{array}$ & $\begin{array}{l}0.300^{*} \\
(0.109)\end{array}$ & $\begin{array}{l}0.305^{*} \\
(0.109)\end{array}$ & $\begin{array}{l}0.277^{* *} \\
(0.109)\end{array}$ & $\begin{array}{l}0.253^{* *} \\
(0.106)\end{array}$ & $\begin{array}{l}0.257^{* *} \\
(0.106)\end{array}$ \\
\hline $\begin{array}{l}R \text {-squared } \\
\text { Agreeableness }\end{array}$ & 0.028 & 0.055 & 0.041 & 0.050 & 0.043 & 0.083 & 0.086 \\
\hline Sexual abuse & $\begin{array}{l}0.138 \\
(0.190)\end{array}$ & $\begin{array}{l}0.101 \\
(0.187)\end{array}$ & $\begin{array}{l}0.145 \\
(0.190)\end{array}$ & $\begin{array}{l}0.088 \\
(0.190)\end{array}$ & $\begin{array}{l}0.170 \\
(0.191)\end{array}$ & $\begin{array}{l}0.073 \\
(0.189)\end{array}$ & $\begin{array}{l}0.119 \\
(0.187)\end{array}$ \\
\hline Being slapped & $\begin{array}{l}0.003 \\
(0.081)\end{array}$ & $\begin{array}{l}0.025 \\
(0.080)\end{array}$ & $\begin{array}{l}0.000 \\
(0.081)\end{array}$ & $\begin{array}{l}-0.012 \\
(0.081)\end{array}$ & $\begin{array}{l}-0.006 \\
(0.081)\end{array}$ & $\begin{array}{l}-0.002 \\
(0.081)\end{array}$ & $\begin{array}{l}0.003 \\
(0.080)\end{array}$ \\
\hline Left alone & $\begin{array}{l}0.031 \\
(0.068)\end{array}$ & $\begin{array}{l}0.019 \\
(0.068)\end{array}$ & $\begin{array}{l}0.032 \\
(0.068)\end{array}$ & $\begin{array}{l}0.020 \\
(0.068)\end{array}$ & $\begin{array}{l}0.026 \\
(0.069)\end{array}$ & $\begin{array}{l}0.009 \\
(0.068)\end{array}$ & $\begin{array}{l}0.007 \\
(0.067)\end{array}$ \\
\hline Neglect of needs & $\begin{array}{l}-0.158 \\
(0.098)\end{array}$ & $\begin{array}{l}-0.130 \\
(0.097)\end{array}$ & $\begin{array}{l}-0.157 \\
(0.098)\end{array}$ & $\begin{array}{l}-0.176^{* * * *} \\
(0.098)\end{array}$ & $\begin{array}{l}-0.145 \\
(0.098)\end{array}$ & $\begin{array}{l}-0.148 \\
(0.097)\end{array}$ & $\begin{array}{l}-0.148 \\
(0.096)\end{array}$ \\
\hline \multicolumn{8}{|l|}{ Conscientiousness } \\
\hline Sexual abuse & $\begin{array}{l}-0.028 \\
(0.212)\end{array}$ & $\begin{array}{l}-0.096 \\
(0.209)\end{array}$ & $\begin{array}{l}-0.014 \\
(0.212)\end{array}$ & $\begin{array}{l}-0.000 \\
(0.212)\end{array}$ & $\begin{array}{l}0.061 \\
(0.213)\end{array}$ & $\begin{array}{l}0.001 \\
(0.209)\end{array}$ & $\begin{array}{l}0.025 \\
(0.209)\end{array}$ \\
\hline Being slapped & $\begin{array}{l}-0.021 \\
(0.090)\end{array}$ & $\begin{array}{l}-0.029 \\
(0.089)\end{array}$ & $\begin{array}{l}-0.022 \\
(0.090)\end{array}$ & $\begin{array}{l}-0.012 \\
(0.090)\end{array}$ & $\begin{array}{l}-0.051 \\
(0.090)\end{array}$ & $\begin{array}{l}-0.050 \\
(0.089)\end{array}$ & $\begin{array}{l}-0.048 \\
(0.089)\end{array}$ \\
\hline Left alone & $\begin{array}{l}-0.007 \\
(0.077)\end{array}$ & $\begin{array}{l}-0.010 \\
(0.075)\end{array}$ & $\begin{array}{l}-0.005 \\
(0.077)\end{array}$ & $\begin{array}{l}-0.018 \\
(0.076)\end{array}$ & $\begin{array}{c}-0.001 \\
(0.077)\end{array}$ & $\begin{array}{l}-0.007 \\
(0.075)\end{array}$ & $\begin{array}{l}-0.009 \\
(0.075)\end{array}$ \\
\hline Neglect of needs & $\begin{array}{l}-0.249^{* * *} \\
(0.109)\end{array}$ & $\begin{array}{l}-0.253^{* *} \\
(0.108)\end{array}$ & $\begin{array}{l}-0.246^{* *} \\
(0.109)\end{array}$ & $\begin{array}{l}-0.236^{* *} \\
(0.109)\end{array}$ & $\begin{array}{l}-0.229^{* *} \\
(0.109)\end{array}$ & $\begin{array}{l}-0.242^{* *} \\
(0.107)\end{array}$ & $\begin{array}{l}-0.242^{* *} \\
(0.107)\end{array}$ \\
\hline$R$-squared & 0.013 & 0.031 & 0.015 & 0.030 & 0.023 & 0.054 & 0.056 \\
\hline
\end{tabular}




$\begin{array}{llllllll}\begin{array}{l}\text { Open to Experience } \\ \text { Sexual abuse }\end{array} & -0.182 & -0.224 & -0.193 & -0.146 & -0.140 & -0.171 & -0.120 \\ & (0.203) & (0.200) & (0.202) & (0.203) & (0.203) & (0.200) & (0.199) \\ \text { Being slapped } & -0.035 & -0.054 & -0.035 & -0.022 & -0.049 & -0.054 & -0.057 \\ & (0.086) & (0.085) & (0.086) & (0.086) & (0.086) & (0.085) & (0.085) \\ \text { Left alone } & 0.077 & 0.070 & 0.062 & 0.064 & 0.065 & 0.043 & 0.041 \\ & (0.073) & (0.072) & (0.073) & (0.073) & (0.073) & (0.072) & (0.072) \\ \text { Neglect of needs } & -0.275^{*} & -0.271^{*} & -0.261^{* *} & -0.273^{*} & -0.257^{* *} & -0.262^{* *} & -0.267^{*} \\ & (0.105) & (0.103) & (0.104) & (0.104) & (0.104) & (0.103) & (0.102) \\ R \text {-squared } & 0.011 & 0.024 & 0.026 & 0.023 & 0.018 & 0.047 & 0.055\end{array}$

Notes: Standard errors in parentheses.

${ }^{*} p<0.01$.

$* * p<0.05$.

*** $p<0.1$.

Estimated coefficient on binary variable of type of maltreatment is interpreted as standard-deviation change in personality trait $k$. Each regression model is estimated with a siblings fixed effects model (2,319 siblings). The baseline model (1) includes controls for age, gender, family characteristics, and birth-weight. Subsequent columns (2)-(5) add separately a block of variables - adolescent personality, adolescent cognitive ability, adolescent physical health problems, and adolescent mental health problems - respectively. The all-controls model (6) includes all control variables simultaneously. Model (7) adds adult socioeconomic status variables (education, earnings) to model (6). Full estimation results for the full model reported in column (7) is reported in Table 11 Technical Appendix.

The most important finding is that, when considering the nature and intensity of maltreatment, we obtain significant and robust associations between neuroticism and sexual abuse or neglect, and between conscientiousness and openness to experience and neglect. In the baseline model, the association between neuroticism and sexual abuse is almost $0.50 \mathrm{SD}$ (significant at the $5 \%$ level), while its association with neglect is $0.32 \mathrm{SD}$ (significant at the $1 \%$ level). The relationship between neuroticism and sexual abuse remains the same when including cognitive ability, but the association is reduced by $20 \%$ when controlling for physical health $(0.42$ $\mathrm{SD})$ or mental health problems (0.39 SD). Interestingly, the association increases by $16 \%$ when controlling for adolescent personality (0.58 SD). Including all control variables simultaneously leaves us with an association of $0.45 \mathrm{SD}$, which is significant at the $5 \%$ level. Less than $10 \%$ of this association is explained by differences in adulthood SES (0.41 SD).

The association between neglect and neuroticism is stable across the various control variable specifications, ranging between $0.32 \mathrm{SD}$ (baseline) and $0.25 \mathrm{SD}$ (all controls). Mental health problems have the largest influence on the association, as they explain $13 \%$ of the relationship (a change from 0.32 SD in column (1) to 0.28 SD in column (5)). Controlling for all potential pathways simultaneously reduces the association between neglect and neuroticism by $21 \%$. Adulthood SES has no influence on the association.

Similarly, the negative association between neglect and conscientiousness ranges between -0.25 SD (baseline) and -0.24 SD (all controls), and they are significant at the $5 \%$ level. The largest reduction in this association is driven by mental health problems, but they explain less than $10 \%$ of the association (a change from $-0.25 \mathrm{SD}$ in column (1) to -0.23 SD in column (5)). Similar to the relationship between neuroticism and neglect, adulthood SES does not explain the association between conscientiousness and neglect. We find identical stable associations between openness to experience and neglect, which range between -0.28 SD (baseline) and -0.26 SD (all controls), and they are statistically significant at the $1 \%$ level. Finally, there is tentative evidence that siblings who felt that they were frequently left alone, relative to their sibling, are more extraverted than their sibling in young adulthood, although the association is smaller in magnitude, ranging between 0.13 SD (baseline) and 0.12 SD (all controls) and it is statistically significant, at best, at the $10 \%$ level.

As a consequence, we conclude that sexual abuse experiences are only associated with young adulthood neuroticism, while experiences of neglect are associated with higher levels of neuroticism, and lower levels of conscientiousness and openness to experience. The most important pathway via which these experiences affect young adulthood personality is mental health problems. In the next section, we therefore assess whether these adverse experiences - maltreatment and subsequent mental or physical health problems - explain the strong relationship between young adulthood personality and adulthood wages or education outcomes that have been documented in e.g. Fletcher (2013) and Lundberg (2013) using Add Health data.

\section{Do Adverse Childhood Experiences Mediate the Relationship between Adult Outcomes and Personality?}

We reestimate the same OLS models as reported in Fletcher (2013), Table 4) and Lundberg (2013, Table 1) to predict log earnings (models $(1 \mathrm{a}),(1 \mathrm{~b}))$ or the probability to obtain a college degree (models $(2 \mathrm{a}),(2 \mathrm{~b}))$ with the 
Big Five personality traits, both measured in Wave 4. In models (a), we only control for family SES, ethnicity, education, cognitive ability, number of siblings, and geographic region. In models (b), we control additionally for adverse childhood experiences (maltreatment and physical and mental health problems). The estimation results are reported in Table 4 .

Table 4: Estimated relationship between earnings or education and personality with and without controlling for childhood health and maltreatment indicators (Reported: marginal effects).

\begin{tabular}{|c|c|c|c|c|c|c|}
\hline & \multicolumn{6}{|c|}{ Dependent variable } \\
\hline & $\begin{array}{l}\text { Log Earnings } \\
\text { (1a) }\end{array}$ & $\begin{array}{l}\text { Log Earnings } \\
\text { (1b) }\end{array}$ & $\%$ Diff & $\begin{array}{l}\text { College } \\
\text { degree } \\
(2 a)\end{array}$ & $\begin{array}{l}\text { College } \\
\text { degree } \\
(2 b)\end{array}$ & $\%$ Diff \\
\hline Extraversion & $\begin{array}{l}0.050^{*} \\
(0.014)\end{array}$ & $\begin{array}{l}0.048^{*} \\
(0.014)\end{array}$ & -4 & $\begin{array}{l}-0.018^{*} \\
(0.004)\end{array}$ & $\begin{array}{l}-0.020^{*} \\
(0.004)\end{array}$ & 8.7 \\
\hline Neuroticism & $\begin{array}{l}-0.086^{*} \\
(0.017)\end{array}$ & $\begin{array}{c}-0.074^{*} \\
(0.016)\end{array}$ & -14 & $\begin{array}{l}-0.042^{*} \\
(0.004)\end{array}$ & $\begin{array}{l}-0.031^{*} \\
(0.004)\end{array}$ & $26^{* *}$ \\
\hline $\begin{array}{l}\text { Agreeable- } \\
\text { ness }\end{array}$ & $\begin{array}{l}0.014 \\
(0.019)\end{array}$ & $\begin{array}{l}0.009 \\
(0.018)\end{array}$ & -35.7 & $\begin{array}{l}0.042^{*} \\
(0.005)\end{array}$ & $\begin{array}{l}0.042^{*} \\
(0.005)\end{array}$ & 1.7 \\
\hline $\begin{array}{l}\text { Conscien- } \\
\text { tious. }\end{array}$ & $\begin{array}{l}0.042 * \\
(0.015)\end{array}$ & $\begin{array}{l}0.023 \\
(0.015)\end{array}$ & $-45.2^{* *}$ & $\begin{array}{l}0.022 * \\
(0.004)\end{array}$ & $\begin{array}{l}0.013^{*} \\
(0.004)\end{array}$ & $38.4^{* *}$ \\
\hline Openness & $\begin{array}{l}-0.026 \\
(0.017)\end{array}$ & $\begin{array}{l}-0.029^{* * * *} \\
(0.016)\end{array}$ & 11.5 & $\begin{array}{l}0.030^{*} \\
(0.004)\end{array}$ & $\begin{array}{l}0.031^{*} \\
(0.004)\end{array}$ & 1.4 \\
\hline $\begin{array}{l}\text { Family } \\
\text { Background } \\
\text { and Cognitive } \\
\text { Ability }\end{array}$ & Yes & Yes & & Yes & Yes & \\
\hline $\begin{array}{l}\text { Childhood } \\
\text { health and } \\
\text { maltreatment }\end{array}$ & No & Yes & & No & Yes & \\
\hline Observations & 8,195 & 8,195 & & 10,693 & 10,693 & \\
\hline$R$-squared & 0.106 & 0.134 & & 0.2174 & 0.2404 & \\
\hline
\end{tabular}

Notes: All models control for the full set of family background variables and cognitive ability as in Fletcher (2013) for earnings and in Lundberg (2013) for the probability to obtain a college degree. Outcomes and personality are measured in Wave 4. Models (1a) and (1b) are estimated with ordinary least squares. Models (2a) and (b) are estimated with a linear probability model.

$* p<0.01$

$* * p<0.05$.

$* * * p<0.1$.

Overall, the estimates of the effect of personality on earnings or the probability to obtain a college degree do not change when controlling for adverse childhood experiences. One important exception is that the estimated coefficient of the effect of conscientiousness on both earnings and educational attainment is significantly reduced when moving from models (a) to (b). In the base model for log earnings (1a), a 1 SD increase in conscientiousness is associated with a $4.2 \%$ increase in earnings. In the full model (1b), this effect drops significantly by $45 \%$ to $2.3 \%$, which is not statistically different from zero. A similar result is obtained for educational attainment. In the base model for educational attainment (2a), a 1 SD increase in conscientiousness is associated with a 2.2 percentage point increase in the probability of obtaining a college degree. When also controlling for childhood maltreatment experiences and adolescent health (2b), this association drops significantly by $38 \%$ to 1.3 percentage points. The effect of neuroticism on educational attainment is also significantly reduced by $26 \%$. This suggests that the productivity and human capital-boosting effects of conscientiousness are fully and partially, respectively, explained by adverse childhood experiences.

\section{Discussion}

This study tests to which degree the Big Five personality traits, a commonly used domain to proxy NCS, have their origins in childhood maltreatment experiences. We use a large, nationally representative sample of young US Americans and exploit S-FE models to control for the potentially confounding effects of shared environments and genes. Some adverse childhood experiences predict significantly and robustly neuroticism, conscientiousness, and openness to experience, but they have no consistent impact on agreeableness and extraver- 
sion. Neuroticism is the only trait significantly associated with experience of frequent sexual abuse. Frequent parental neglect experiences are positively associated with neuroticism and negatively associated with conscientiousness and openness to experiences.

Our findings must be considered in light of some important limitations. The amount of variation in sexual abuse between siblings may be too small to detect statistically significant effects, which is a general limitation of S-FE models (Conley, Pfeiffer, and Velez 2007; Bound and Solon 1999). For instance, the associations between sexual abuse and agreeableness or openness are sizable (0.14 SD and $-0.18 \mathrm{SD})$, but their standard errors are too large to detect effects with certainty $(0.19$ and 0.20$)$.

We are also not able to fully control for reporting differences that are linked to personality. This leaves open the possibility that some of the estimated effects are driven by differences in the willingness to report maltreatment that also correlate with personality. It is impossible to say for certain that the treatment effect of parental neglect on neuroticism, conscientiousness, and openness to experience are true differences in exposure between siblings. More neurotic personalities may be more likely to inflate negative experiences such as neglect - leading to false positives - while more open personalities may be more likely to share harmful experiences. In both cases, we would overestimate the effect of maltreatment on personality. On the other hand, frequent sexual abuse is likely to be underreported because of its stigma and criminal nature. Memories of sexual abuse may even be repressed, a phenomenon that is referred to as "dissociative amnesia," which finds strong scientific support (Scheflin and Brown 1996). Due to these false negatives, we are likely to underestimate the true effect of sexual abuse on neuroticism. The alternative to self-reported maltreatment data is administrative data on substantiated abuse and neglect from child protection services. Although more accurate, such data tend to severely underreport the occurrence of maltreatment (Petersen, Joseph, \& Feit 2014). For this reason, most major studies rely on self-reported data (e.g. Felitti et al. 1998; Currie and Tekin 2012; Hengartner et al. 2015).

Although our results cannot be given a causal interpretation, they provide a clearer picture of what adulthood personality traits may capture. Importantly, the strong associations observed between conscientiousness and adulthood productivity and educational attainment are partially explained by these adverse childhood experiences. Our findings are useful to applied researchers who seek to explore the meaning of the estimated associations between adulthood personality and labor market outcomes. These findings complement the knowledge we have already about the correlates of openness to experience with intelligence (see Almlund et al. 2011 for an overview). Our results also emphasize the important role of the earlier-life family environment in shaping personality. Thus, the findings are useful to policy makers who search for windows of opportunity to boost children's NCS through family policy.

\section{Funding}

The authors acknowledge financial support from an Australian Research Council Early Career Discovery Program Grant (DE140100463) and the Australian Research Council Centre of Excellence for Children and Families over the Life Course (project number CE140100027). This research uses data from Add Health, a program project directed by Kathleen Mullan Harris and designed by J. Richard Udry, Peter S. Bearman, and Kathleen Mullan Harris at the University of North Carolina at Chapel Hill, and funded by grant P01-HD31921 from the Eunice Kennedy Shriver National Institute of Child Health and Human Development, with cooperative funding from 23 other federal agencies and foundations. Special acknowledgment is due Ronald R. Rindfuss and Barbara Entwisle for assistance in the original design. Information on how to obtain the Add Health data files is available on the Add Health website (http:/ / www.cpc.unc.edu/addhealth). No direct support was received from grant P01-HD31921 for this analysis. 


\section{Notes}

${ }^{1}$ The American Psychological Association Dictionary (2007) describes these as follows: 1. Openness to experience (Intellect) - The tendency to be open to new aesthetic, cultural, or intellectual experiences. 2. Conscientiousness - The tendency to be organized, responsible, and hardworking. 3. Extraversion - An orientation of one's interests and energies toward the outer world of people and things rather than the inner world of subjective experience, characterized by positive affect and sociability. 4. Agreeableness - The tendency to act in a cooperative, unselfish manner. 5. Neuroticism (vs. emotional stability) - A chronic level of emotional instability and proneness to psychological distress.

${ }^{2}$ It is possible that parenting styles in general are the consequence of a child's temperament, which means that parents adjust their parenting styles to the child's needs and temperament (e.g. Deal et al. 2005). Because of this simultaneity of parenting, temperament, and health, modeling the effect of parenting behavior is empirically challenging. Some studies exploited birth order - an exogenous variation in differential parental treatment - to test whether parenting behavior affects adulthood personality, but find little evidence in favor of it (e.g. Marini and Kurtz 2011; Sulloway 1996). Research on China's One-Child Policy (OCP), a natural institutional experiment that led to concentrated attention on one child by all caretakers, found that children born just after the introduction of the OCP in 1979 tended to be less conscientious, more neurotic, and less optimistic than children born just before (Cameron et al. 2013).

${ }^{3}$ In our full estimation sample, Cronbach's alpha for each dimension is: conscientiousness 0.64 , openness to experience 0.61 , extraversion 0.70 , agreeableness 0.68 , and neuroticism 0.85 .

${ }^{4}$ The same measures have been used in Fletcher (2013) and Lundberg (2013).

${ }^{5}$ Self-reported measures of maltreatment are error prone. Currie and Tekin (2012) discuss the potential pitfalls of these measures, but refer to methodological papers that have shown that, "if collected properly, these data are valid" (p. 515). The participants of the AddHealth study were asked to listen to prerecorded questions on sensitive topics through earphones and to enter their answers directly on laptops. This process ensured confidentiality and minimized the potential for interviewer or other third-party influence. In order to obtain accurate responses about the timing of events, the study members were prompted with a calendar that gave the dates of many important events. While recall bias is an important consideration for these measures, the bias could be small because the respondents were young adults when asked about childhood maltreatment. This has the advantage that young adults are mature enough to understand and report on such events (see Perkonigg et al. 2000). Another advantage is that the time window over which the respondents recall past events is relatively short (10 years on average).

${ }^{6}$ The factor structure of the items indicates that each measures only one construct and the three factor scores have internal consistency estimates ranging between 0.76 and 0.86 , which are similar to the reliability coefficients for the adulthood NEO personality instruments measured with 3 to 10 times as many items (Young and Beaujean 2011, Table 5).

${ }^{7}$ Instead of investigating the role of adolescent personality as possible mediator via which maltreatment affects adulthood personality, we could have included it as standard control variable in the benchmark model. This is a commonly used strategy in the literature on noncognitive skill formation referred to as the value-added model. Such model assumes that adolescent personality is a valid proxy for previous inputs, for instance parenting behavior including maltreatment, and educational opportunities (see Cunha and Heckman 2008 for an overview of these models).

${ }^{8}$ Furthermore, it is also possible that the mediator variables measured in adolescence and personality measured in adulthood are strongly correlated only because they measure imperfectly the same underlying trait. This is possible if maltreatment experiences cause, e.g. mental health problems in adolescence, which is an imperfect proxy of personality in adolescence, while adolescent and young adulthood personality are strongly correlated (see Elkins, Kassenboehmer, and Schurer 2017 for evidence of the latter). We thank an anonymous referee for having pointed out this possibility.

${ }^{9}$ We alert that this last estimation model cannot exclude the possibility of reverse causality, because adult personality traits are measured in the same time period as adulthood SES.

${ }^{10}$ We have tested for the possibility that maltreatment experiences have differential effects for children from low and high SES background. For this reason, we have interacted the maltreatment measure with indicators for high and low levels of education of the mother. We find no statistically significant interaction effect of maltreatment on any of the five personality traits. The exception is for agreeableness. Children from high SES backgrounds who experience a higher level of maltreatment than their sibling tend to be less agreeable in adulthood than their siblings ( $-0.18 \mathrm{SD}$, significant at the $1 \%$ level). Full results are provided upon request.

\section{References}

Almlund, M., A.L. Duckworth, J.J. Heckman, and T.D. Kautz. 2011. “Personality Psychology and Economics." In Handbook of the Economics of Education., edited by E.A. Hanushek, S. Machin, and L. Woessmann, Vol. 4, 1-182. Amsterdam: North-Holland, Elsevier Science.

American Psychological Association. 2007. APA Dictionary of Psychology Washington, DC: American Psychological Association.

Asendorpf, J.B., J.J.A. Denissen, and M.A.C. Van Aken. 2008. “Inhibited and Aggressive Preschool Children at 23 Years of Age: Personality and Social Transitions into Adulthood." Developmental Psychology 44: 997-1011.

Attanasio, O., S. Cattan, E. Fitzsimons, C. Meghir, and M. Rubio-Codina. 2015. “Estimating the Production Function for Human Capital: Results from a Randomized Control Trial in Colombia." NBER Working Paper Nr. 20965.

Baldasaro, R.E., M.J. Shanahan, and D.J. Bauer. 2013. "Psychometric Properties of the Mini-Ipip in a Large, Nationally Representative Sample of Young Adults." Journal of Personality Assessment 95 (1): 74-84.

Borghans, L., B.H.H. Golsteyn, J.J. Heckman, and J.E. Humphries. 2011. "Identification Problems in Personality Psychology ." Personality and Individual Differences 51 (3): 315-320.

Borkenau, P., R. Riemann, F.M. Spinath, and A. Angleitner. 2001. “Cenetic and Environmental Influences on Observed Personality: Evidence from the German Observational Study of Adult Twins." Journal of Personality and Social Psychology 80: 655-668.

Bound, J., and G. Solon. 1999. "Double Trouble: On the Value of Twins-Based Estimation of the Return to Schooling." Economics of Education Review 18 (2): 169-182.

Cameron, L., N. Erkal, L. Gangadharan, and X. Meng. 2013. “Little Emperors: Behavioral Impacts of China's One-Child Policy .” Science 339 (6122): 953-957. 
Caspi, A., H.L. Harrington, B. Milne, J.W. Amell, R.F. Theodore, and T.E. Moffitt. 2003. “Children's Behavioral Styles at Age 3 are Linked to Their Adult Personality Traits at Age 26." Journal of Personality 71 (4): 1467-6494.

Caspi, A., and B.W. Roberts. 2001. "Personality Development across the Life Course: The Argument for Change and Continuity." Psychological Inquiry 12: 49-66.

Caspi, A., B.W. Roberts, and R.L. Shiner. 2005. “Personality Development: Stability and Change." Annual Review of Psychology 56: 453-484.

Caspi, A., and P. Silva. 1995. “Temperamental Qualities at Age 3 Predict Personality Traits in Young Adulthood: Longitudinal Evidence from a Birth Cohort." Child Development 66: 486-498.

Clark, C., T. Caldwell, C. Power, and S.A. Stansfeld. 2010. "Does the Influence of Childhood Adversity on Psychopathology Persist across the Lifecourse? A 45-Year Prospective Epidemiologic Study." Annals of Epidemiology 20 (5): 385-394.

Cobb-Clark, D.A., and S. Schurer. 2012. "The Stability of Big-Five Personality Traits ." Economics Letters 115: 11-15.

Cobb-Clark, D.A., N. Salamanca, and A. Zhu. 2016. "Parenting Style as an Investment in Human Development." IZA Discussion Paper No. 9686, IZA Bonn.

Conley, D., K.M. Pfeiffer, and M. Velez. 2007. “Explaining Sibling Differences in Achievement and Behavioral Outcomes: The Importance of Within- and Between-Family Factors." Social Science Research 36: 1087-1104.

Costa, P.T., and R.R. McCrae. 1992. NEO Personality Inventory (NEO-PI-R) and NEO Five-Factor Inventory (NEO-FFI) Professional Manual. Odessa, FL: Psychological Assessment Resources Inc.

Cunha, F., and J.J. Heckman. 2008. "Formulating, Identifying and Estimating the Technology of Cognitive and Noncognitive Skill Formation ." Journal of Human Resources 43 (4): 738-782.

Cunha, F., J.J. Heckman, and S.M. Schennach. 2010. “Estimating the Technology of Cognitive and Noncognitive Skill Formation ." Econometrica 78 (3): 883-931.

Currie, J., and E. Tekin. 2012. “Understanding the Cycle: Childhood Maltreatment and Future Crime?." The Journal of Human Resources 47 (2): 509-549.

Dahmann, S., and S. Anger. 2014. “The impact of education on personality: Evidence from a Cerman high school reform. Discussion Paper 8139, IZA Bonn".

Deal, J.E., C.F. Halverson, V. Havill, and R.P. Martin. 2005. “Temperament Factors as Longitudinal Predictors of Young Adult Personality ." Merrill-Palmer Quarterly 51: 315-334.

Del Bono, E., M. Francesconi, Y. Kelly, and A. Sacker. 2014. “Early Maternal Time Investment and Early Child Outcomes .” IZA Discussion Paper Nr 8608. IZA Bonn.

Donnellan, M.B., F.L. Oswald, B.M. Baird, and R.E. Lucas. 2006. “The Mini-Ipip Scales: Tiny-Yet-Effective Measures of the Big Five Factors of Personality." Psychological Assessment 18 (2): 192-203.

Eisenberg, N., A.L. Duckworth, T.L. Spinrad, and C. Valiente. 2014. “Conscientiousness: Origins in Childhood?.” Developmental Psychology 50 (5): 1331-1349.

Elkins, R., S.C. Kassenboehmer, and S. Schurer. 2017. “The Stability of Personality Traits during Adolescence and Young Adulthood ." Journal of Economic Psychology. Available online 6 January 2017. DOI:10.1016/j.joep.2016.12.005.

Felitti, V.J., R.F. Anda, D. Nordenberg, D.F. Williamson, A.M. Spitz, V. Edwards, M.P. Koss, and J.S. Marks. 1998. "Relationship of Childhood Abuse and Household Dysfunction to Many of the Leading Causes of Death in Adults: The Adverse Childhood Experiences (ACE) Study ." American Journal of Preventive Medicine 14 (4): 245-258.

Filer, R.K. 1986. "The Role of Personality and Tastes in Determining Occupational Structure." Industrial Labor Relations Review XX: 412-424.

Fletcher, J., and B. Wolfe. 2009. "Long-Term Consequences of Childhood ADHD on Criminal Activities." The Journal of Mental Health Policy and Economics 12 (3): 119-138.

Fletcher, J.M. 2009. "Childhood Mistreatment and Adolescent and Young Adult Depression ." Social Science \& Medicine 68: 799-806.

Fletcher, J.M. 2011. "The Medium Term Schooling and Health Effects of Low Birth Weight: Evidence from Siblings ." Economics of Education Review 30: 517-527.

Fletcher, J.M. 2013. "The Effects of Personality Traits on Adult Labor Market Outcomes: Evidence from Siblings ." Journal of Economic Behavior $\delta$ Organization 89 (C): 122-135.

Fletcher, J.M., and M.R. Richards. 2012. “Lower Wages And Employment In Young Adults Diabetes's 'Health Shock' To Schooling And Earnings: Increased Dropout Rates And Lower Wages And Employment In Young Adults ." Health Affairs 31 (1): 27-34.

Fraley, C., and B.W. Roberts. 2005. "Patterns of Continuity: A Dynamic Model for Conceptualizing the Stability of Individual Differences in Psychological Constructs across the Life Course." Psychological Review 112: 60-74.

Galaif, E. R., J.A. Stein, M. D. Newcomb, and D.P. Bernstein. 2001. “Cender Differences in the Prediction of Problem Alcohol Use in Adulthood: Exploring the Influence of Family Factors and Childhood Maltreatment." Journal of Studies on Alcohol 62: 486-493.

Censowski, M. 2014. “Personality, IQ, and Lifetime Earnings." IZA Discussion Paper Series 8235. June. IZA Bonn.

Coldberg, L.R., J.A. Johnson, H.W. Eber, R. Hogan, M.C. Ashton, C.R. Cloninger, and H.G. Cough. 2006. "The International Personality Item Pool and the Future of Public-Domain Personality Measures." Journal of Research in Personality 40: 84-96.

Coodwin, R.G., and H.S. Friedman. 2006. "Health Status and the Five Factor Personality Traits in a Nationally Representative Sample ." Journal of Health Psychology 11: 643-654.

Hampson, S.E., L.R. Coldberg, T.M. Vogt, and J.P. Dubanoski. 2006. “Forty Years On: Teacher's Assessments of Children's Personality Traits Predict Self-Reported Health Behaviors and Outcomes at Midlife." Health Psychology 25: 57-64.

Heckman, J.J., and T. Kautz. 2012. "Hard Evidence on Soft Skills." Labour Economics 19: 451-464.

Heineck, G., and S. Anger. 2010. "The Returns to Cognitive Abilities and Personality Traits in Cermany." Labour Economics 17 (3): $535-546$.

Hengartner, M.P., L.]. Cohen, S. Rodgers, M. Müller, W. Rössler, and V. Ajdacic-Cross. 2015. “Association between Childhood Maltreatment and Normal Adult Personality Traits: Exploration of an Understudied Field ." Journal of Personality Disorders 29 (1): 1-14.

Judge, T.A., C.A. Higgins, C.J. Thoresen, and M.R. Barrick. 1999. “The Big Five Personaltiy Traits, Ceneral Mental Ability, and Career Success across the Life Span ." Personality Psychology 52: 621-652. 
Kaufman, J., B. Yang, H. Douglas-Palomberi, S. Houshyar, D. Lipschitz, et al. 2004. “Social Supports and Serotonin Transporter Cene Moderate Depression in Maltreated Children ." Proceedings of the National Academy of Sciences 101: 17316-17321.

Kern, M.L., and H.S. Friedman. 2008. “Do Conscientious Individuals Live Longer? A Quantitative Review.” Health Psychology 27: 505-512.

Kern, M.L., H.S. Friedman, L.R. Martin, C.A. Reynolds, and G. Luong. 2009. “Conscientiousness, Career Success, and Longevity: A Lifespan Analysis ." Annals of Behavioral Medicine 37: 154-163.

Koenen, K., T. Moffitt, A. Caspi, A. Taylor, and S. Purcell. 2003. “Domestic Violence Is Associated with Environmental Suppression of IQ in Young Children." Development and Psychopathology 15: 297-311.

Koenig, A.L., D. Cicchetti, and F.A. Rogosch. 2004. "Moral Development: The Association between Maltreatment and Young Children's Prosocial Behaviors and Moral Transgressions." Social Development 4 (13): 97-106.

Krueger, R.F., and N. Eaton. 2010. "Personality Traits and the Classification of Mental Disorders: Toward a More Complete Integration in DSM-V and an Empirical Model of Psychopathology." Personality Disorder: Theory, Research, and Treatment 1 (2): 97-118.

Krueger, R.F., S. South, W. Johnson, and W.G. lacono. 2008. “The Heritability of Personality Is Not Always 50 \%: Cene-Environment Interactions and Correlations between Personality and Parenting." Journal of Personality 76 (6): 1485-1521.

Lüdtke, O., B.W. Roberts, U. Trautwein, and G. Nagy. 2011. “A Random Walk down University Avenue: Life Paths, Life Events, and Personality Trait Change at the Transition to University Life." Journal of Personality and Social Psychology 101 (3): 620.

Luhmann, M., U. Orth, J. Specht, C. Kandler, and R.E. Lucas. 2014. "Studying Changes in Life Circumstances and Personality: It's about Time ." European Journal of Personality 28: 256-266.

Lundberg, S. 2013. “The College Type: Personality and Educational Inequality." Journal of Labor Economics 31 (3): 421-441.

Marini, V.A., and J.E. Kurtz. 2011. "Birth Order Differences in Normal Personality Traits: Perspectives from within and outside the Family ." Personality and Individual Differences 51: 910-914.

McAdams, D.P., and B.D. Olson. 2010. “Personality Development: Continuity and Change over the Life Course." Annual Review of Psychology 61: 517-542.

McCrae, R.R., and P.T. Costa. 2008. “A Five-Factor Theory of Personality." In Handbook of Personality: Theory and Research., edited by L.A. Pervin, O.P. John, and R.W. Robins, Vol. 3, 159-181. New York: Guilford Press.

McCrae, R.R., P.T. Costa, F. Ostendorf, A. Angleitner, M. Hrebickova, M.D. Avia, et al. 2000. “Nature over Nurture: Temperament, Personality, and Life Span Development." Journal of Personality and Social Psychology 78: 173-186.

McKinnon, D.P., A.J. Fairchild, and M.S. Fritz. 2007. "Mediation Analysis." Annual Review of Psychology 58: 593-614.

Miilunpalo, Seppo, Vuori, Ilkka, Oja, Pekka, Matti, Pasanen, Urponen, and Helka. 1997. “Self-rated Health Status as a Health Measure: The Predictive Value of Self-Reported Health Status on the Use of Physician Services and on Mortality in the Working-Age Population." Journal of Clinical Epidemiology 50 (5): 517-528.

Moffitt, T.E., L. Arseneault, D. Belsky, N. Dickson, R.J. Hancox, H. Harrington, R. Houts, R. Poulton, B.W. Roberts, S. Ross, M.R. Sears, W.M. Thomson, and A. Caspi. 2011. "A Gradient of Childhood Self-Control Predicts Health, Wealth, and Public Safety." Proceedings of the National Academy of Sciences 108: 2693-2698.

Mueller, G., and E. Plug. 2006. "Estimating the Effects of Personality on Male and Female Earnings." Industrial and Labor Relations Review 60 (1): 3-22.

Perkonigg, A., R. Kessler, S. Storz, and H. Wittchen. 2000. “Traumatic Events and Post-Traumatic Stress Disorder in the Community: Prevalence, Risk Factors and Comorbidity." Acta Psychiatrica Scandinavica 101 (1): 46-59.

Perry, B.D., R. Pollard, T. Blakely, W. Baker, and D. Vigilante. 1995. "“'Childhood Trauma, the Neurobiology of Adaptation and” UseDependent" Development of the Brain: How “States" Become "Traits"." Infant Mental Health Journal 16: 271-291.

Petersen, A.C., J. Joseph, and M. Feit. 2014. New Directions in Child Abuse and Neglect Research. Washington, DC: National Academies Press (US) 25(4), Consequences of Child Abuse and Neglect.

Poropat, A.E. 2009. "A Meta-Analysis of the Five-Factor Model of Personality and Academic Performance." Psychological Bulletin 135: 322-338.

Putnam, F. 2006. "The Impact of Trauma on Child Development." Juvenile and Family Court Journal 1-11. Winter.

Roberts, B.W., and W.F. DelVecchio. 2000. "The Rank-Order Consistency of Personality Traits from Childhood to Old Age: A Quantitative Review of Longitudinal Studies." Psychological Bulletin 126: 3-25.

Roberts, B.W., N.R. Kuncel, R. Shiner, A. Caspi, and L.R. Coldberg. 2007. “The Power of Personality: The Comparative Validity of Personality Traits, Socioeconomic Status, and Cognitive Ability for Predicting Important Life Outcomes." Perspectives on Psychological Science 2 (4): 313-345.

Roberts, R., P. Lewinsohn, and J. Seeley. 1991. “Screening for Adolescent Depression: A Comparison of Depression Scales." Journal of the American Academy for Child Adolescent Psychiatry 30 (1): 58-66.

Roberts, B.W., and D. Mroczek. 2008. “Personality Trait Change in Adulthood ." Current Directions in Psychological Science 17: 31-35.

Roberts, B.W., K. Walton, and W. Viechtbauer. 2006. “Patterns of Mean-Level Change in Personality Traits across the Life Course: A MetaAnalysis of Longitudinal Studies." Psychological Bulletin 132: 1-25.

Roberts, B.W., D. Wood, and A. Caspi. 2008. “The Development of Personality Traits in Adulthood.” In Handbook of Personality: Theory and Research., edited by O.P. John, R.W. Robins, and L.A. Pervin, Vol. 14, 3rd 375-398. New York, NY: Guilford.

Roberts, B.W., D. Wood, and J.L. Smith. 2005. "Evaluating the Five Factor Theory and Social Investment Perspective on Personality Trait Development." Journal of Research in Personality 39: 166-184.

Samuel, D.B., and T.A. Widiger. 2008. "A Meta-Analytic Review of the Relationships between the Five-Factor Model and DSM-IV-TR Personality Disorders: A Facet Level Analysis." Clinical Psychology Review 28: 1326-1342.

Scheflin, A.W., and D. Brown. 1996. “Repressed Memory or Dissociative Amnesia: What the Science Says ." Journal of Psychiatry and Law 24: 143-188.

Schurer, S., S. Kassenboehmer, and F. Leung. 2015. “Do Universities Shape Their Students' Personality? ." IZA Discussion Paper Nr. 8873, IZA Bonn. 
Specht, J., W. Bleidorn, J.J.A. Denissen, M. Hennecke, R. Hutteman, C. Kandler, M. Luhmann, U. Orth, A.K. Reitz, and J. Zimmermann. 2014. "What Drives Adult Personality Development? A Comparison of Theoretical Perspectives and Empirical Evidence ." European Journal of Personality 28: 216-230.

Specht, J., B. Egloff, and S.C. Schmukle. 2011. “Stability and Change of Personality Across the Life Course: The Impact of Age and Major Life Events on Mean-Level and Rank-Order Stability of the Big Five." Journal of Personality and Social Psychology 101: 862-882.

Spila, B., M. Makara, G. Kozak, and A. Urbanska. 2008. “Abuse in Childhood and Mental Disorder in Adult Life." Child Abuse Review 17 (2): 133-138.

Sulloway, F.]. 1996. Born to Rebel: Birth Order Family Dynamics, and Creative Lives. New York: Pantheon Books.

Trull, T..., and T.A. Widiger. 2013. "Dimensional Models of Personality: The Five-Factor Model and the DSM-5." Dialogues in Clinical Neuroscience 15 (2): 135-146.

Turkheimer, E. 2000. "Three Laws of Behavior Cenetics and What They Mean ." Current Directions in Psychological Science 9: 160-164.

Turkheimer, E., A. Haley, M. Waldron, B. D’Onofrio, and I.I. Cottesman. 2003. “Socioeconomic Status Modifies Heritability of IQ in Young Children ." Psychological Science 14 (6): 623-628.

Tyrka, A.R., M.C. Wyche, M.M. Kelly, L.H. Price, and L.L. Carpenter. 2009. “Childhood Maltreatment and Adult Personality Disorder Symptoms: Influence of Maltreatment Type." Psychiatry Research 165 (3): 281-287.

Udry, J.R 2003. The National Longitudinal Study of Adolescent Health (Add Health), Waves I, II \& III, 1994-2001. Chapel Hill: Carolina Population Center, University of North Carolina at Chapel Hill [Machine-readable data file and documentation].

Widiger, A.T., E. Simonsen, R. Krueger, W.J. Livesley, and R. Verheul. 2005. “Personality Disorder Research Agenda for the New DSM-V ." Journal of Personality Disorder 19 (3): 315-338.

Widiger, T.A., and T.J. Trull. 2007. "Plate Tectonics in the Classification of Personality Disorder: Shifting to a Dimensional Model ." American Psychologist 62: 71-83.

Widom, C.S., S.J. Czaja, T. Bentley, and M.S. Johnson. 2012. "A Prospective Investigation of Physical Health Outcomes in Abused and Neglected Children: New Findings from A 30-Year Follow-Up ." American Journal of Public Health 102 (6): 1135-1144.

Widom, C.S., S.J. Czaja, and J. Paris. 2009. "A Prospective Investigation of Borderline Personality Disorder in Abused and Neglected Children Followed up into Adulthood." Journal of Personality Disorders 23 (5): 433-446.

Widom, C.S., K. DuMont, and S.]. Czaja. 2007. "A Prospective Investigation of Major Depressive Disorder and Comorbidity in Abused and Neglected Children Grown Up." Archives of Ceneral Psychiatry 64 (1): 49-56.

Young, J.K., and A.A. Beaujean. 2011 (July) 13. "Measuring Personality in Wave 1 of the National Longitudinal Study of Adolescent Health ." Frontiers in Psychology. DOI:10.3389/fpsyg.2011.00158

\section{Technical Appendix}

Table 5: Descriptive statistics.

\begin{tabular}{|c|c|c|c|c|c|}
\hline \multirow[b]{2}{*}{ Variable (W: Wave) } & \multicolumn{2}{|c|}{ Full sample $N=10,693$} & \multicolumn{2}{|c|}{ Siblings sample $N=2,319$} & \multirow[t]{2}{*}{ Diff. Sign.* } \\
\hline & Mean & SD & Mean & SD & \\
\hline Extraversion (W4) & 13.28 & 3.06 & 13.26 & 3.06 & \\
\hline Neuroticism (W4) & 10.37 & 2.73 & 10.40 & 2.77 & \\
\hline Agreeableness (W4) & 15.30 & 2.39 & 15.29 & 2.40 & \\
\hline Conscientiousness (W4) & 14.69 & 2.69 & 14.80 & 2.66 & $* *$ \\
\hline Openness (W4) & 14.56 & 2.44 & 14.36 & 2.44 & $* * *$ \\
\hline Age (W4) & 28.91 & 1.75 & 28.81 & 1.77 & $* * *$ \\
\hline Female & 0.54 & 0.50 & 0.54 & 0.50 & \\
\hline Missing family inform. (W1) & 0.30 & 0.46 & 0.29 & 0.45 & \\
\hline Log(birthweight) (W1) & 1.96 & 0.20 & 1.89 & 0.24 & $* * *$ \\
\hline Birthweight missing (W1) & 0.17 & 0.38 & 0.17 & 0.37 & \\
\hline Sex abuse (W3) & 0.01 & 0.09 & 0.01 & 0.10 & \\
\hline Physical abuse (W3) & 0.06 & 0.24 & 0.07 & 0.25 & \\
\hline Left alone (W3) & 0.09 & 0.28 & 0.09 & 0.29 & \\
\hline Basic needs not met (W3) & 0.03 & 0.16 & 0.03 & 0.18 & \\
\hline PVT score (W1) & 0.13 & 0.93 & 0.03 & 0.91 & $* * *$ \\
\hline Math grade (W1) & 2.48 & 1.23 & 2.49 & 1.23 & \\
\hline General health (W1) & 3.90 & 0.91 & 3.90 & 0.90 & \\
\hline Obese (W1) & 0.07 & 0.26 & 0.08 & 0.26 & \\
\hline Obese missing (W1) & 0.02 & 0.15 & 0.02 & 0.15 & \\
\hline Asthma (W4) & 0.15 & 0.35 & 0.15 & 0.35 & \\
\hline Diabetes (W4) & 0.03 & 0.16 & 0.02 & 0.16 & \\
\hline Difficulty with hands (W1) & 0.01 & 0.09 & 0.01 & 0.07 & \\
\hline Difficulty with feet (W1) & 0.02 & 0.12 & 0.02 & 0.13 & \\
\hline Epilepsy (W1) & 0.01 & 0.11 & 0.02 & 0.12 & \\
\hline
\end{tabular}




\begin{tabular}{|c|c|c|c|c|c|}
\hline Blindness (W1) & 0.00 & 0.07 & 0.01 & 0.08 & \\
\hline Diffic. with feet miss. (W1) & 0.13 & 0.33 & 0.12 & 0.33 & \\
\hline Diffic. with hands miss. (W1) & 0.13 & 0.33 & 0.12 & 0.33 & \\
\hline Depressed (W1) & 0.08 & 0.26 & 0.09 & 0.28 & \\
\hline ADHD (W4) & 0.05 & 0.21 & 0.04 & 0.20 & \\
\hline Learning disability (W1) & 0.11 & 0.28 & 0.11 & 0.29 & \\
\hline Learning disab. missing (W1) & 0.14 & 0.34 & 0.13 & 0.34 & \\
\hline Conscientiousness (W1) & -0.01 & 1.00 & 0.01 & 1.02 & \\
\hline Neuroticism (W1) & -0.03 & 0.95 & -0.05 & 0.92 & \\
\hline Extraversion (W1) & 0.02 & 1.00 & 0.06 & 0.98 & \\
\hline Missing conscient. (W1) & 0.01 & 0.10 & 0.01 & 0.09 & \\
\hline Missing extraversion (W1) & 0.32 & 0.47 & 0.37 & 0.48 & $* * *$ \\
\hline Education (W4) & 14.44 & 2.07 & 14.33 & 2.09 & $* * *$ \\
\hline Earnings (W4) & 36.97 & 38.91 & 34.49 & 32.51 & $* * *$ \\
\hline
\end{tabular}

* Note: Test result whether difference in means between full and estimation sample differ. $* *<5 \%$.

$* * *<1 \%$.

Table 6: Determinants of probability to be in the siblings sample.

\begin{tabular}{ll}
\hline Variables & $\begin{array}{l}\text { Coef. } \\
\text { (SE) }\end{array}$ \\
\hline Maternal education & 0.003 \\
& $(0.003)$ \\
Family income (10,000s) & $0.001^{* *}$ \\
& $(0.000)$ \\
Black family & -0.006 \\
Constant & $(0.016)$ \\
& $0.355^{* *}$ \\
Observations & $(0.040)$ \\
$R$-squared & 5,470 \\
\hline
\end{tabular}

Notes: Linear probability model. Standard errors in parentheses.

${ }^{*} p<0.01$.

$* * p<0.05$.

$* * * 0<0.1$.

Table 7: The Big Five personality traits measured in Wave 4.

Conscientiousness $(\mathrm{C})$

Openness to experience $(\mathrm{O})$

Neuroticism $(\mathrm{N})$
Characteristics are related to being reliable, responsible, and having self-control versus impulsivity and casualness

H4PE3 3. I get chores done right away

H4PE11 11. I often forget to put things back in their proper place

H4PE19 19. I like order

H4PE27 27. I make a mess of things

Characteristics are associated with the willingness to have new experiences, engage new ideas, and be open to one's own feelings versus being cynical and tough-minded

H4PE5 5. I have a vivid imagination

H4PE13 13. I am not interested in abstract ideas

H4PE21 21. I have difficulty understanding abstract ideas

H4PE29 29. I do not have a good imagination

Characteristics are related to anxiety and emotional liability versus being placid and emotionally stable

H4PE4 4. I have frequent mood swings

H4PE6 6. I worry about things

H4PE8 8. I get angry easily

H4PE12 12. I am relaxed most of the time

H4PE14 14. I am not easily bothered by things

H4PE16 16. I rarely get irritated 
H4PE20 20. I get upset easily

H4PE22 22. I get stressed out easily

H4PE24 24. I lose my temper

H4PE28 28. I seldom feel blue

H4PE32 32. I keep my cool

Extraversion (E)

Characteristics are associated with enthusiasm toward life's circumstances, outgoing, and surgency versus introversion gravity; encounter with oneself and one's life circumstances

H4PE1 1. I am the life of the party

H4PE9 9. I don't talk a lot

H4PE17 17. I talk to a lot of different people at parties

H4PE25 25. I keep in the background

Characteristics are related to an inclination toward submission to others, passivity,

Agreeableness (A) and subduedness versus being independent and having a strong will

H4PE2 2. I sympathize with others' feelings

H4PE10 10. I am not interested in other people's problems

H4PE18 18. I feel others' emotions

H4PE26 26. I am not really interested in others

Note: Factor analysis is used to predict the first principal factor from the four questions each. Scores are standardized to mean o and standard deviation 1.

Table 8: Personality questionnaire Wave 1 (as suggested by Young and Beaujean 2011).

\begin{tabular}{|c|c|}
\hline \multirow{6}{*}{ Neuroticism } & You have a lot of good qualities* H1PF 30 \\
\hline & You have a lot to be proud of* H1PF 32 \\
\hline & You like yourself just the way you are* H1PF33 \\
\hline & You feel like you are doing everything just about right ${ }^{*}$ H1PF34 \\
\hline & You feel socially accepted ${ }^{*}$ H1PF35 \\
\hline & You feel wanted and loved* H1PF36 \\
\hline \multirow{3}{*}{ Extraversion } & I feel close to people at school ${ }^{* *}$ S62B \\
\hline & I feel like I am a part of this school** S62E \\
\hline & I feel socially accepted ${ }^{* *} \mathrm{~S} 62 \mathrm{O}$ \\
\hline \multirow[t]{4}{*}{ Conscientiousness } & $\begin{array}{l}\text { When you have a problem to solve, one of the first things you do is get as many } \\
\text { facts about the problem as possible* H1PF18 }\end{array}$ \\
\hline & $\begin{array}{l}\text { When you are attempting to find a solution to a problem, you usually try to think } \\
\text { of as many different ways to approach the problem as possible* H1PF19 }\end{array}$ \\
\hline & $\begin{array}{l}\text { When making decisions, you generally use a systematic method for judging and } \\
\text { comparing alternatives* H1PF20 }\end{array}$ \\
\hline & $\begin{array}{l}\text { After carrying out a solution to a problem, you usually try to analyze what went } \\
\text { right and what went wrong* H1PF21 }\end{array}$ \\
\hline
\end{tabular}

Note: Childhood temperament was part of Wave 1; Young and Beaujean (2011) demonstrate the construct validity of the each facet. Cronbach's alpha for neuroticism, extraversion, and conscientiousness is $0.86,0.76$, and 0.76 , respectively.

Table 9: Mental and physical health measures.

Physical health
General Health: A general health status measure is constructed from a question asked in Wave 1: "In general, how is your health?". The cohort members could respond with poor, fair, good, very good, or excellent. Despite the subjectivity of this variable, research has shown that it is a strong predictor of objective health measures such as mortality and health care utilization (Miilunpalo et al. 1997). Asthma: We construct a binary measure of asthma from information collected in Wave 3, when the young adult respondents were asked whether they have "ever been diagnosed with asthma." 
Diabetes: Information on self-reported diabetes status was not collected until Wave 4. The key question posed to respondents was, "Has a doctor, nurse, or other health care provider ever told you that you have or had high blood sugar or diabetes?" Those answering yes for either condition were also asked for their age at diagnosis. We coded our childhood diabetes variable to take the value 1 if the individual reported that it was diagnosed before the age of 18 . The same measure has been used in Fletcher and Richards (2012) to predict human capital accumulation. The disadvantage of this measure is that it does not allow us to distinguish between Type I and Type II diabetes.

Obesity: A measure of obesity - an indicator of excessive body fat - is constructed from clinically assessed height and weight information obtained in Wave 2. BMI is defined as weight in kilograms divided by height in meters squared. Obesity is defined as a BMI greater than 30.

Gross motor problems: We generate binary variables that indicate problems with hands or feet (Wave 1) which are likely to affect the development of fine and gross motor skills, and epilepsy (by Wave 3).

Depression: We use 19 of the 20 items of the Center for Epidemiological Studies Depression Scale (CES-D) contained in Wave 1. The scale ranges from 0 to 57, and we use a cut-off score of 22 for male adolescents and 24 for females to construct a binary measure of depression as recommended in Robert et al. (1991). This scale has been used to examine adolescent depression and has been shown to have good measurement properties (see Fletcher (2009)).

Learning disability: To construct an indicator variable for whether the child has a learning disability, we use the following question given to the parent respondent in Wave 1: "Does (he/she) have a specific learning disability, such as difficulties with attention, dyslexia, or some other reading, spelling, writing, or math disability?". The same indicator was used in Fletcher (2011).

ADHD: We follow Fletcher and Wolfe (2009) to construct an indicator of childhood ADHD symptoms from 18 questions collected during Wave 3 . The questions ask respondents to think back to when they were between 5 and 12 years of age and report how often they performed a set of behaviors (e.g., squirmed in their seat, had difficulty sustaining attention in tasks). Retrospective ratings of previous health should be used with caution when examining adult outcomes. Yet, several reviews have concluded that childhood experiences are recalled with sufficient accuracy to provide useful information in retrospective studies.

Table 10: Full estimation results including all control variables (excluding adult socioeconomic status).

\begin{tabular}{|c|c|c|c|c|c|c|c|c|c|c|}
\hline & \multicolumn{5}{|l|}{ OLS } & \multicolumn{5}{|c|}{ Siblings fixed effects } \\
\hline & $\begin{array}{l}\text { Extra } \\
\text { (1) }\end{array}$ & $\begin{array}{l}\text { Neur } \\
(2)\end{array}$ & $\begin{array}{l}\text { Agree } \\
\text { (3) }\end{array}$ & $\begin{array}{l}\text { Consc } \\
\text { (4) }\end{array}$ & $\begin{array}{l}\text { Open } \\
(5)\end{array}$ & $\begin{array}{l}\text { Extra } \\
\text { (1) }\end{array}$ & $\begin{array}{l}\text { Neur } \\
(2)\end{array}$ & $\begin{array}{l}\text { Agree } \\
\text { (3) }\end{array}$ & $\begin{array}{l}\text { Consc } \\
\text { (4) }\end{array}$ & $\begin{array}{l}\text { Open } \\
\text { (5) }\end{array}$ \\
\hline \multirow[t]{2}{*}{ Maltreatment (Std) } & & & & & & & & & & 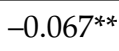 \\
\hline & $(0.030)$ & & & & $(0.0$ & $(0.0$ & $(0.0$ & & & \\
\hline \multirow[t]{2}{*}{ Age } & -0.016 & 0.001 & 0.011 & $0.020^{* * *}$ & $-0.032^{*}$ & -0.001 & -0.007 & & $0.026^{* * *}$ & $-0.030^{* *}$ \\
\hline & $(0.012)$ & $(0.012)$ & $(0.012)$ & $(0.012)$ & $(0.012)$ & $(0.013)$ & $(0.014)$ & $(0.012)$ & $(0.014)$ & $(0.013)$ \\
\hline \multirow[t]{2}{*}{ Female } & 0.030 & & & & -0.2 & 0.061 & $0.275^{*}$ & & $0^{*}$ & $-0.132^{*}$ \\
\hline & $(0.043)$ & $(0.0$ & $(0.0$ & $(0.0$ & $(0.0$ & $(0.046)$ & $(0.047)$ & & $(0.0$ & $(0.1$ \\
\hline \multirow[t]{2}{*}{ Family inform. miss. } & 0.031 & -0.0 & -0.040 & -0.0 & 0.002 & -0.0 & -0.1 & -0.1 & $-0.220^{*}$ & -0 . \\
\hline & $(0.052)$ & $(0.05$ & $(0.0$ & & & $(0.0$ & $(0.0$ & $(0.070)$ & $(0.077)$ & $(0.074)$ \\
\hline \multirow[t]{2}{*}{ Log birthweight } & 0.063 & -0.052 & -0.104 & 0.043 & -0.101 & -0.035 & -0.018 & 0.037 & 0.104 & 0.133 \\
\hline & $(0.086)$ & $(0.084)$ & $(0.083)$ & $(0.084)$ & $(0.083)$ & $(0.130)$ & $(0.132)$ & $(0.120)$ & $(0.133)$ & $(0.127)$ \\
\hline \multirow[t]{2}{*}{ Birthweight missing } & -0.038 & -0.0 & 0.23 & 0.08 & 0.21 & -0.091 & $-0.188^{* * *}$ & $0.257^{* *}$ & 0.164 & 0.10 \\
\hline & $(0.098)$ & $(0.095)$ & $(0.094)$ & $(0.0 s$ & $(0.094)$ & $(0.109)$ & $(0.111)$ & $(0.101)$ & $(0.112)$ & $(0.107)$ \\
\hline \multirow[t]{2}{*}{ PVT score Wave 1} & -0.019 & $-0.110^{*}$ & $0.164^{*}$ & $-0.063^{*}$ & $0.250^{*}$ & $-0.101^{*}$ & $-0.085^{*}$ & -0.029 & $-0.069^{* *}$ & $0.139^{*}$ \\
\hline & $(0.024)$ & $(0.023)$ & & & & & & & & \\
\hline \multirow[t]{2}{*}{ Math grade Wave 1} & 0.006 & $-0.040^{* * *}$ & 0.025 & 0.04 & -0.014 & 0.028 & $-0.052^{* *}$ & 0.004 & 0.0 & 0.013 \\
\hline & $(0.021)$ & $(0.021)$ & $(0.020)$ & $(0.021)$ & $(0.021)$ & $(0.021)$ & $(0.022)$ & $(0.020)$ & & $(0.021)$ \\
\hline \multirow[t]{2}{*}{ Math grade missing } & -0.020 & 0.030 & -0.007 & -0.039 & 0.021 & -0.129 & -0.027 & -0.034 & 0.010 & -0.095 \\
\hline & & & $(0.091)$ & $(0.092)$ & & $(0.092)$ & $(0.094)$ & $(0.086)$ & & $(0.091)$ \\
\hline \multirow{2}{*}{$\begin{array}{l}\text { General health Wave } \\
1\end{array}$} & $0.061^{* *}$ & -0.024 & 0.025 & 0.029 & $0.063^{*}$ & $0.042^{* * *}$ & -0.025 & 0.022 & $0.073^{*}$ & 0.025 \\
\hline & $(0.025)$ & $(0.024)$ & $(0.024)$ & $(0.024)$ & $(0.024)$ & $(0.024)$ & $(0.025)$ & (0.023) & $(0.025)$ & $(0.024)$ \\
\hline Obesity Wave 1 & 0.129 & -0.018 & -0.051 & $-0.241^{*}$ & 0.016 & 0.104 & 0.001 & -0.033 & $-0.172^{* *}$ & -0.130 \\
\hline
\end{tabular}




\begin{tabular}{|c|c|c|c|c|c|c|c|c|c|c|}
\hline & $(0.080)$ & $(0.078)$ & $(0.076)$ & $(0.078)$ & $(0.077)$ & $(0.083)$ & $(0.084)$ & $(0.077)$ & $(0.085)$ & $(0.081)$ \\
\hline \multirow[t]{2}{*}{ Obesity Missing } & 0.047 & -0.099 & 0.176 & 0.110 & 0.015 & -0.050 & $-0.229^{* * *}$ & -0.071 & -0.053 & -0.029 \\
\hline & $(0.134)$ & $(0.130)$ & $(0.128)$ & $(0.130)$ & $(0.129)$ & $(0.133)$ & $(0.135)$ & $(0.123)$ & $(0.136)$ & $(0.130)$ \\
\hline \multirow[t]{2}{*}{ Asthma Wave 4} & 0.039 & $0.139^{* *}$ & 0.067 & -0.039 & $0.129^{* *}$ & 0.030 & 0.081 & -0.039 & 0.062 & 0.029 \\
\hline & $(0.058)$ & $(0.057)$ & $(0.056)$ & $(0.057)$ & $(0.056)$ & $(0.056)$ & $(0.057)$ & $(0.052)$ & $(0.057)$ & $(0.055)$ \\
\hline \multirow[t]{2}{*}{ Diabetes Wave 4} & 0.032 & $0.415^{*}$ & 0.090 & -0.079 & -0.127 & 0.028 & $0.547^{*}$ & $0.345^{*}$ & -0.188 & $-0.371^{*}$ \\
\hline & $(0.131)$ & $(0.128)$ & $(0.126)$ & $(0.127)$ & $(0.126)$ & $(0.125)$ & $(0.127)$ & $(0.116)$ & $(0.128)$ & $(0.123)$ \\
\hline \multirow[t]{2}{*}{ Diff. hands Wave 1} & 0.078 & -0.048 & 0.154 & -0.314 & -0.031 & 0.004 & -0.309 & 0.024 & 0.407 & 0.167 \\
\hline & $(0.326)$ & $(0.317)$ & $(0.313)$ & $(0.317)$ & $(0.314)$ & $(0.306)$ & $(0.311)$ & $(0.283)$ & $(0.314)$ & $(0.300)$ \\
\hline \multirow[t]{2}{*}{ Difficulty feet Wave 1} & 0.198 & $0.277^{* * *}$ & -0.031 & 0.051 & 0.071 & 0.261 & -0.124 & -0.175 & 0.034 & -0.073 \\
\hline & $(0.171)$ & $(0.166)$ & $(0.164)$ & $(0.166)$ & $(0.165)$ & $(0.172)$ & $(0.175)$ & $(0.159)$ & $(0.176)$ & $(0.169)$ \\
\hline \multirow[t]{2}{*}{ Epilepsy Wave 4} & 0.205 & $0.272^{* * *}$ & -0.057 & -0.243 & -0.115 & 0.243 & 0.196 & -0.159 & $-0.293^{* * *}$ & 0.115 \\
\hline & $(0.159)$ & $(0.154)$ & $(0.152)$ & $(0.154)$ & $(0.153)$ & $(0.148)$ & $(0.151)$ & $(0.137)$ & $(0.152)$ & $(0.145)$ \\
\hline \multirow[t]{2}{*}{ Blindness Wave 4} & 0.054 & 0.349 & -0.224 & -0.310 & 0.039 & -0.258 & 0.223 & $-0.752^{*}$ & -0.270 & -0.357 \\
\hline & $(0.291)$ & $(0.283)$ & $(0.279)$ & $(0.283)$ & $(0.281)$ & $(0.272)$ & $(0.277)$ & $(0.252)$ & $(0.279)$ & $(0.267)$ \\
\hline \multirow[t]{2}{*}{ Diff feet missing } & $-0.659^{* * *}$ & 0.287 & -0.463 & 0.197 & -0.134 & -0.065 & 0.578 & -0.415 & -0.327 & -0.502 \\
\hline & $(0.393)$ & $(0.382)$ & $(0.376)$ & $(0.382)$ & $(0.379)$ & $(0.369)$ & $(0.375)$ & $(0.341)$ & $(0.378)$ & $(0.362)$ \\
\hline \multirow[t]{2}{*}{ Diff hands missing } & 0.533 & -0.145 & 0.458 & 0.201 & 0.288 & 0.117 & -0.202 & 0.365 & 0.351 & $0.766^{* *}$ \\
\hline & $(0.379)$ & $(0.369)$ & $(0.363)$ & $(0.369)$ & $(0.366)$ & $(0.353)$ & $(0.359)$ & $(0.327)$ & $(0.362)$ & $(0.346)$ \\
\hline \multirow[t]{2}{*}{ Depressed Wave 1} & 0.124 & $0.317^{*}$ & -0.008 & 0.106 & 0.089 & 0.005 & $0.157^{* *}$ & -0.020 & $0.168^{* *}$ & -0.003 \\
\hline & $(0.079)$ & $(0.077)$ & $(0.076)$ & $(0.077)$ & $(0.077)$ & $(0.072)$ & $(0.073)$ & $(0.067)$ & $(0.074)$ & $(0.071)$ \\
\hline \multirow[t]{2}{*}{ ADHD Wave 4} & 0.042 & 0.108 & 0.043 & $-0.276^{*}$ & 0.103 & -0.073 & 0.170 & -0.002 & $-0.206^{* * *}$ & 0.060 \\
\hline & $(0.107)$ & $(0.104)$ & $(0.103)$ & $(0.104)$ & $(0.103)$ & $(0.108)$ & $(0.110)$ & $(0.100)$ & $(0.111)$ & $(0.106)$ \\
\hline \multirow{2}{*}{$\begin{array}{l}\text { Learning disab. } \\
\text { Wave } 1\end{array}$} & -0.047 & 0.082 & $-0.114^{* * *}$ & $-0.227^{*}$ & $-0.215^{*}$ & -0.004 & 0.084 & $-0.119^{* * *}$ & $-0.243^{*}$ & $-0.176^{* *}$ \\
\hline & $(0.072)$ & $(0.070)$ & $(0.069)$ & $(0.070)$ & $(0.070)$ & & $(0.076)$ & $(0.069)$ & & $(0.073)$ \\
\hline \multirow{2}{*}{$\begin{array}{l}\text { Learning disability } \\
\text { missing }\end{array}$} & 0.030 & -0.035 & -0.206 & $-0.471^{*}$ & -0.238 & 0.009 & 0.008 & -0.013 & -0.202 & -0.164 \\
\hline & $(0.171)$ & $(0.166)$ & $(0.163)$ & $(0.166)$ & $(0.164)$ & $(0.162)$ & $(0.165)$ & $(0.150)$ & $(0.166)$ & $(0.159)$ \\
\hline \multirow{2}{*}{$\begin{array}{l}\text { Conscientiousness } \\
\text { Wave } 1\end{array}$} & -0.027 & 0.006 & -0.030 & $-0.092^{*}$ & $-0.052^{* *}$ & $-0.041^{* *}$ & 0.011 & 0.016 & $-0.075^{*}$ & $-0.048^{* *}$ \\
\hline & $(0.021)$ & $(0.021)$ & $(0.021)$ & $(0.021)$ & $(0.021)$ & $(0.021)$ & $(0.021)$ & $(0.020)$ & $(0.022)$ & $(0.021)$ \\
\hline \multirow[t]{2}{*}{ Neuroticism Wave 1} & $-0.140^{*}$ & $0.092^{*}$ & -0.009 & $-0.108^{*}$ & $-0.073^{*}$ & $-0.104^{*}$ & $0.131^{*}$ & $-0.069^{*}$ & $-0.087^{*}$ & $-0.057^{* *}$ \\
\hline & $(0.027)$ & $(0.026)$ & $(0.026)$ & $(0.026)$ & $(0.026)$ & & & & $(0.028)$ & $(0.027)$ \\
\hline \multirow[t]{2}{*}{ Extraversion Wave 1} & $0.106^{*}$ & $-0.073^{*}$ & $0.061^{*}$ & 0.028 & 0.008 & $0.069^{*}$ & -0.034 & $0.044^{* * *}$ & 0.033 & 0.001 \\
\hline & $(0.022)$ & $(0.021)$ & $(0.021)$ & $(0.021)$ & $(0.021)$ & $(0.022)$ & $(0.022)$ & $(0.020)$ & $(0.023)$ & $(0.022)$ \\
\hline \multirow{2}{*}{$\begin{array}{l}\text { Conscientiousness } \\
\text { Wave } 1 \text { Missing }\end{array}$} & $-0.361^{* * *}$ & -0.081 & -0.127 & 0.214 & 0.153 & 0.001 & $-0.423^{* * *}$ & -0.112 & 0.136 & 0.197 \\
\hline & $(0.218)$ & $(0.212)$ & $(0.208)$ & $(0.212)$ & $(0.210)$ & $(0.227)$ & $(0.231)$ & $(0.210)$ & $(0.233)$ & $(0.223)$ \\
\hline \multirow{2}{*}{$\begin{array}{l}\text { Extraversion Wave } 1 \\
\text { Missing }\end{array}$} & 0.018 & $0.090^{* *}$ & -0.063 & 0.000 & -0.019 & 0.012 & 0.031 & -0.041 & 0.011 & $-0.109^{* *}$ \\
\hline & (0.043) & $(0.042)$ & $(0.042)$ & $(0.042)$ & (0.042) & $(0.044)$ & $(0.045)$ & (0.041) & (0.045) & (0.043) \\
\hline \multirow{2}{*}{\multicolumn{11}{|c|}{$\begin{array}{l}\text { Education Wave } 4 \\
\text { Earnings Wave } 4\end{array}$}} \\
\hline & & & & & & & & & & \\
\hline \multirow{2}{*}{ Constant } & 0.052 & -0.026 & -0.475 & $-0.777^{* * *}$ & $0.914^{* *}$ & -0.062 & 0.292 & $-1.259^{*}$ & $-1.208^{* *}$ & 0.620 \\
\hline & $(0.442)$ & $(0.430)$ & $(0.423)$ & $(0.430)$ & $(0.426)$ & $(0.509)$ & $(0.518)$ & $(0.471)$ & $(0.521)$ & (0.499) \\
\hline Observations & 2,319 & 2,319 & 2,319 & 2,319 & 2,319 & 2,319 & 2,319 & 2,319 & 2,319 & 2,319 \\
\hline$R$-squared & 0.051 & 0.120 & 0.102 & 0.073 & 0.105 & 0.036 & 0.081 & 0.122 & 0.052 & 0.046 \\
\hline
\end{tabular}

Note: Personality traits are standardized to mean o and standard deviation 1 . Standard errors in parentheses.

${ }^{*} p<0.01$.

** $p<0.05$.

$* * * p<0.1$.

Table 11: Full estimation results with indicator variables for maltreatment type (siblings fixed effects model).

\begin{tabular}{|c|c|c|c|c|c|}
\hline & $\begin{array}{l}\text { Extra } \\
\text { (1) }\end{array}$ & $\begin{array}{l}\text { Neur } \\
(2)\end{array}$ & $\begin{array}{l}\text { Agree } \\
\text { (3) }\end{array}$ & $\begin{array}{l}\text { Consc } \\
\text { (4) }\end{array}$ & $\begin{array}{l}\text { Open } \\
\text { (5) }\end{array}$ \\
\hline Sexual abuse & $\begin{array}{l}-0.033 \\
(0.203)\end{array}$ & $\begin{array}{l}0.410^{* *} \\
(0.207)\end{array}$ & $\begin{array}{l}0.119 \\
(0.187)\end{array}$ & $\begin{array}{l}0.025 \\
(0.209)\end{array}$ & $\begin{array}{l}-0.120 \\
(0.199)\end{array}$ \\
\hline Being slapped & $\begin{array}{l}0.022 \\
(0.087)\end{array}$ & $\begin{array}{l}0.002 \\
(0.088)\end{array}$ & $\begin{array}{l}0.003 \\
(0.080)\end{array}$ & $\begin{array}{l}-0.048 \\
(0.089)\end{array}$ & $\begin{array}{l}-0.057 \\
(0.085)\end{array}$ \\
\hline Left alone & $\begin{array}{l}0.118 \\
(0.073)\end{array}$ & $\begin{array}{l}0.068 \\
(0.074)\end{array}$ & $\begin{array}{l}0.007 \\
(0.067)\end{array}$ & $\begin{array}{l}-0.009 \\
(0.075)\end{array}$ & $\begin{array}{l}0.041 \\
(0.072)\end{array}$ \\
\hline
\end{tabular}


Neglect of needs

Age

Female

Family inform. miss.

Log birthweight

Birthweight missing

PVT score Wave 1

Math grade Wave 1

Math grade missing

General health Wave 1

Obesity Wave 1

Obesity missing

Asthma Wave 4

Diabetes Wave 4

Diff. hands Wave 1

Difficulty feet Wave 1

Epilepsy Wave 4

Blindness Wave 4

Diff feet missing

Diff hands missing

Depressed Wave 1

ADHD Wave 4

Learning disab. Wave 1

Learning disability missing

Conscientiousness Wave 1

Neuroticism Wave 1

Extraversion Wave 1

Conscientiousness Wave 1

missing

Extraversion Wave 1 missing

Education Wave 4

Earnings Wave 4

Constant$$
\text { (0.104) }
$$

$-0.008$

(0.013)

0.045

(0.047)

$-0.030$

(0.075)

$-0.068$

(0.130)

$-0.085$

(0.109)

$-0.121^{*}$

(0.031)

0.013

(0.022)

$-0.099$

(0.093)

0.034

(0.024)

0.102

(0.083)

$-0.044$

(0.132)

0.030

(0.056)

0.086

(0.125)

0.065

(0.305)

0.269

(0.171)

$0.243^{* * *}$

(0.148)

$-0.252$

(0.273)

$-0.048$

(0.367)

0.056

(0.353)

0.014

(0.072)

$-0.056$

(0.108)

0.028

(0.075)

0.045

(0.162)

$-0.043^{\text {** }}$

(0.021)

$-0.096^{*}$

(0.027)

$0.067^{*}$

(0.022)

0.002

(0.227)

0.021

(0.044)

$0.044^{*}$

(0.013)

$0.002^{* *}$

(0.001)

$-0.432$

$(0.533)$
$0.257^{* *}$

(0.106)

$-0.004$

(0.014)

$0.285^{*}$

(0.048)

$-0.135^{\text {*** }}$

(0.077)

0.002

(0.132)

$-0.173$

(0.111)

$-0.070^{* *}$

(0.032)

$-0.042^{* * *}$

(0.022)

$-0.058$

(0.094)

$-0.020$

(0.025)

0.004

(0.084)

$-0.234^{* * *}$

(0.135)

0.081

(0.057)

$0.504^{*}$

(0.128)

$-0.345$

(0.311)

$-0.122$

(0.175)

0.189

(0.150)

0.261

(0.278)

0.572

(0.374)

$-0.178$

(0.359)

$0.155^{* *}$

(0.073)

0.149

(0.110)

0.055

(0.076)

$-0.040$

(0.165)

0.011

(0.021)

$0.129^{*}$

(0.028)

$-0.034$

(0.022)

$-0.423^{* * *}$

(0.231)

0.027

(0.045)

$-0.034^{* *}$

(0.014)

$-0.001$

(0.001)

0.663

(0.543)
(0.096)

$0.027^{* *}$

(0.012)

0.589 *

(0.043)

$-0.186^{*}$

(0.069)

0.042

(0.119)

$0.247^{* *}$

(0.100)

$-0.056^{* * *}$

(0.029)

$-0.012$

(0.020)

0.014

(0.085)

0.013

(0.023)

$-0.059$

(0.076)

$-0.054$

(0.122)

$-0.040$

(0.052)

$0.404^{*}$

(0.116)

0.059

(0.281)

$-0.165$

(0.158)

$-0.124$

(0.136)

$-0.730^{*}$

(0.251)

$-0.364$

(0.339)

0.250

(0.325)

$-0.026$

(0.066)

$-0.022$

(0.100)

$-0.076$

(0.069)

0.039

(0.149)

0.013

(0.019)

$-0.063^{* *}$

(0.025)

$0.041^{* *}$

$(0.020)$

$-0.099$

(0.209)

$-0.035$

(0.041)

$0.072^{*}$

(0.012)

$-0.001^{* *}$

(0.001)

$-2.135^{*}$

(0.491)

$-0.242^{* *}$

(0.107)

$0.025^{* * *}$

(0.014)

$0.146^{*}$

(0.048)

$-0.216^{*}$

(0.077)

0.105

(0.133)

0.156

(0.112)

$-0.084^{*}$

(0.032)

$-0.003$

(0.022)

0.032

(0.095)

$0.069^{*}$

(0.025)

$-0.182^{* *}$

(0.085)

$-0.045$

(0.136)

0.061

(0.057)

$-0.161$

(0.129)

0.426

(0.313)

0.020

(0.176)

$-0.275^{* * *}$

(0.152)

$-0.276$

(0.280)

$-0.321$

(0.377)

0.323

(0.362)

$0.164^{* *}$

(0.074)

$-0.218^{* * *}$

(0.111)

$-0.220^{*}$

(0.077)

$-0.175$

(0.166)

$-0.078^{*}$

(0.022)

$-0.083^{*}$

(0.028)

0.031

(0.023)

0.145

(0.233)

0.014

$(0.045)$

$0.034^{* *}$

(0.014) 


\begin{tabular}{llllll} 
Observations & 2,319 & 2,319 & 2,319 & 2,319 & 2,319 \\
$R$-squared & 0.044 & 0.086 & 0.136 & 0.056 & 0.055 \\
\hline
\end{tabular}

Note: Personality traits are standardized to mean o and standard deviation 1 . Standard errors in parentheses.

${ }^{*} p<0.01$.

${ }^{* *} p<0.05$

*** $p<0.1$. 